OPEN ACCESS

Edited by: Yuanlong Pan, Nestlé R\&D, United States

Reviewed by:

Giuseppe Caruso, Associazione Oasi Maria SS. Onlus (IRCCS), Italy

Evelyne Gozal,

University of Louisville, United States

${ }^{*}$ Correspondence:

Donald F. Weaver

dweaver@uhnres.utoronto.ca

Specialty section

This article was submitted to Neuroenergetics, Nutrition and Brain

Health,

a section of the journa

Frontiers in Neuroscience

Received: 25 June 2018

Accepted: 24 September 2018

Published: 12 October 2018

Citation:

Mancini RS, Wang $Y$ and Weaver DF (2018) Phenylindanes in Brewed Coffee Inhibit Amyloid-Beta and Tau Aggregation

Front. Neurosci. 12:735. doi: 10.3389/fnins.2018.00735

\section{Phenylindanes in Brewed Coffee Inhibit Amyloid-Beta and Tau Aggregation}

\author{
Ross S. Mancini', Yanfei Wang ${ }^{1}$ and Donald F. Weaver ${ }^{1,2,3 *}$ \\ ${ }^{1}$ Department of Fundamental Neurobiology, Krembil Research Institute, University Health Network, Toronto, ON, Canada, \\ ${ }^{2}$ Department of Chemistry, University of Toronto, Toronto, ON, Canada, ${ }^{3}$ Department of Medicine, University of Toronto, \\ Toronto, ON, Canada
}

Coffee consumption has been correlated with a decreased risk of developing Alzheimer's disease (AD) and Parkinson's disease (PD), but the mechanism by which coffee may provide neuroprotection in humans is not fully understood. We hypothesized that compounds found in brewed coffee may elicit neuroprotective effects by inhibiting the aggregation of amyloid-beta (A $\beta)$ and tau (AD) or $\alpha$-synuclein (PD). Three instant coffee extracts (light roast, dark roast, decaffeinated dark roast) and six coffee components [caffeine (1), chlorogenic acid (2), quinic acid (3), caffeic acid (4), quercetin (5), and phenylindane (6)] were investigated for their ability to inhibit the fibrillization of $A \beta$ and tau proteins using thioflavin $T(T h T)$ and thioflavin $S$ (ThS) fluorescence assays, respectively. Inhibition of $A \beta$ and $\alpha$-synuclein oligomerization was assessed using ELISA assays. All instant coffee extracts inhibit fibrillization of $A \beta$ and tau, and promote $\alpha$-synuclein oligomerization at concentrations above $100 \mu \mathrm{g} / \mathrm{mL}$. Dark roast coffee extracts are more potent inhibitors of $A \beta$ oligomerization ( $\left(\mathrm{C}_{50} \mathrm{ca} .10 \mu \mathrm{g} / \mathrm{mL}\right.$ ) than light roast coffee extract $\left(\mathrm{IC}_{50}=40.3 \mu \mathrm{g} / \mathrm{mL}\right)$, and pure caffeine (1) has no effect on $A \beta$, tau or $\alpha$-synuclein aggregation. Coffee components $\mathbf{2}, \mathbf{4}$, and $\mathbf{5}$ inhibit the fibrillization of $A \beta$ at $100 \mu \mathrm{M}$ concentration, yet only $\mathbf{5}$ inhibits $A \beta$ oligomerization $\left(I C_{50}=10.3 \mu \mathrm{M}\right)$. 1$\mathbf{5}$ have no effect on tau fibrillization. Coffee component $\mathbf{6}$, however, is a potent inhibitor of both $A \beta$ and tau fibrillization, and also inhibits $A \beta$ oligomerization $\left(\mathrm{IC}_{50}=42.1 \mu \mathrm{M}\right)$. Coffee components $\mathbf{4}$ and $\mathbf{5}$ promote the aggregation of $\alpha$-synuclein at concentrations above $100 \mu \mathrm{M}$; no other coffee components affect $\alpha$-synuclein oligomerization. While the neuroprotective effect of coffee consumption is likely due to a combination of factors, our data suggest that inhibition $A \beta$ and tau aggregation by phenylindane $\mathbf{6}$ (formed during the roasting of coffee beans, higher quantities found in dark roast coffees) is a plausible mechanism by which coffee may provide neuroprotection. The identification of 6 as a dual-inhibitor of both $A \beta$ and tau aggregation is noteworthy, and to our knowledge this is the first report of the aggregation inhibition activity of $\mathbf{6}$.

Keywords: Alzheimer's, Parkinson's, protein misfolding, aggregation inhibition, coffee, caffeine, phenylindane, neuroprotective 


\section{INTRODUCTION}

Coffee is one of the most widely consumed beverages worldwide, with approximately 500 billion cups consumed annually (Butt and Sultan, 2011). Coffee drinks are available in a variety of different flavors, roasting levels, and also with or without caffeine. More recently, coffee has attracted interest in the medical community due to a growing number of epidemiological studies and meta-analyses which have correlated coffee consumption with a reduced risk of developing diabetes mellitus, various cancers and neurodegenerative disorders such as Alzheimer's disease (AD) and Parkinson's disease (PD) (Butt and Sultan, 2011). It is generally accepted that caffeine and caffeinated coffee elicit short-term improvements in alertness, attention and memory (Butt and Sultan, 2011), but the ability to protect against age-related cognitive decline is less clear. A 2010 systematic review and meta-analysis by Santos et al. (2010) suggests that a positive correlation between coffee consumption and dementia prevention is apparent, but inconsistencies in study design and methodology make interpretation of experimental results complicated (Costa et al., 2010). A more recent study by Mirza et al. (2014) claim that there is no correlation between coffee consumption and incident dementia, attributing the perceived neuroprotective benefits to a reverse causality effect.

The major psychoactive component of coffee is caffeine (1), a xanthine alkaloid that readily crosses the blood-brain barrier (BBB). It is known that caffeine content in coffee is highly variable, and depends on the type of coffee bean (Arabica versus Robusta), roasting method (light roast versus dark roast) and extraction method (drip versus boiled) employed. For example, a standard cup of drip coffee contains on average $70-80 \mathrm{mg}$ caffeine per $150 \mathrm{~mL}$ (Barone and Roberts, 1996), whereas espresso coffees contain approximately $950 \mathrm{mg}$ caffeine per $150 \mathrm{~mL}$ (Ludwig et al., 2014). However, given the differences in serving size between a typical $8 \mathrm{oz}$ cup of drip coffee and $1 \mathrm{oz}$ espresso shot, the overall caffeine intake is similar. Caffeine is also highly bioavailable, with nearly $100 \%$ absorption of caffeine occurring 45 min post-ingestion (Blanchard and Sawers, 1983). These favorable drug-like properties have prompted research efforts into the use of caffeine to treat cognitive decline associated with AD (Arendash et al., 2006, 2009) and PD (Chen et al., 2001; Xu et al., 2010). However, it has recently been suggested that chronic caffeine administration may exacerbate behavioral and psychological symptoms of patients with dementia (anxietyrelated behaviors), and could interfere with any potential cognitive benefits of caffeine consumption (Baeta-Corral et al., 2018).

In addition to caffeine, coffee also contains a variety of polyphenolic acids known collectively as chlorogenic acids, as well as various flavinoids, tannins and melanoidans. In fact, transgenic mouse models of $\mathrm{AD}$ that were administered crude caffeine - the byproduct of coffee's decaffeination process, containing a variety of other phytochemicals in addition to caffeine - exhibited less memory impairment and lower hippocampal levels of $A \beta$ peptide and $A \beta$ plaques versus mice treated with pure caffeine (Chu et al., 2012). It has even been suggested that caffeine may have synergistic effects with other components in coffee to produce the overall neuroprotective effect (Cao et al., 2011). Our lab has an interest in identifying naturally occurring small molecules which can inhibit the aggregation of amyloidogenic proteins; the formation of protein aggregates in the brain (in particular pre-fibrillar oligomers) is known to be neurotoxic (Ono, 2017, 2018), and inhibition of the aggregation process is an attractive strategy for the treatment of neurodegenerative disorders. As such, there is a need for the identification of drug-like molecules capable of preventing the aggregation of amyloidogenic proteins associated with $\mathrm{AD}$ $(\mathrm{A} \beta /$ tau $)$ and $\mathrm{PD}$ ( $\alpha$-synuclein) to spur drug discovery projects. It is worth noting, however, that some small molecule inhibitors of protein aggregation exhibit their effects by stabilizing smaller oligomeric species (Dedmon et al., 2005; Taniguchi et al., 2005; Masuda et al., 2006; Zhu et al., 2013; Matos et al., 2017), which have the potential to be neurotoxic (Caruso et al., 2017).

We have recently reported that components of Canadian maple syrup can reduce the aggregation of amyloidogenic $A \beta$ and tau (Hawco et al., 2016), and we were curious if caffeine or other components found in brewed coffee elicit neuroprotective effects through a similar mechanism. Herein we report our investigation into the effects of coffee on the aggregation of misfolded proteins associated with dementia to determine if inhibition of protein aggregation is a viable mechanism of neuroprotection associated with coffee consumption. We show that a number of polyphenolic compounds found in brewed coffee (Figure 1) can alter the aggregation profile of $A \beta$, tau and $\alpha$-synuclein. Of the coffee components investigated, pyrolysis product $\mathbf{6}$ is found to be a potent inhibitor of both $\mathrm{A} \beta$ and tau aggregation, and is the only component tested capable of inhibiting tau aggregation. A related series of indanedione analogs are also known to inhibit $\mathrm{A} \beta$ fibrillization (Catto et al., 2010), but tau aggregation was not investigated in this report. To our knowledge, this is the first report of the aggregation inhibition activity of $\mathbf{6}$ for $A \beta$, tau and $\alpha$-synuclein.

\section{MATERIALS AND METHODS}

\section{Coffee Extracts and Coffee Components}

Starbucks brand 100\% Arabica instant coffee (Starbucks Via Instant ${ }^{\mathrm{TM}}$ ) was obtained in three different varieties: light roast, dark roast and decaffeinated dark roast. Stock solutions of coffee extracts were prepared in water that was micropore filtered and deionized (MilliQ ${ }^{\circledR}$ Advantage A10, Millipore Sigma) at a concentration of $10.0 \mathrm{mg} / \mathrm{mL}$ for in vitro screening. Caffeine (1) was purchased from $\mathrm{BDH}$ biochemical (Mississauga, ON, Canada). Chlorogenic acid (2), quinic acid (3), caffeic acid (4) and quercetin (5) were purchased from Combi-Blocks (San Diego, CA, United States). Phenylindane (6) was prepared as outlined below, according to modified literature procedure (Stadler et al., 1996). Stock solutions of compounds $\mathbf{1 - 4}$ and $\mathbf{6}$ were prepared in $\mathrm{MilliQ}^{\circledR}$ water at a concentration of $25.0 \mathrm{mM}$ for in vitro screening. Stock solution of compound $\mathbf{5}$ was prepared in 
<smiles>Cn1c(=O)c2c(ncn2C)n(C)c1=O</smiles>

1<smiles>O=C(O)/C=C/c1ccc(O)c(O)c1</smiles>

4<smiles>O=C(/C=C/c1ccc(O)c(O)c1)OC1CC(O)(C(=O)O)C[C@H](O)[C@H]1O</smiles>

2<smiles>O=C1C(O)=C(c2ccc(O)c(O)c2)Cc2cc(O)cc(O)c21</smiles>

5<smiles>O=C(O)C1(O)CC(O)[C@@H](O)[C@H](O)C1</smiles>

3<smiles>CC1CC(c2ccc(O)c(O)c2)c2cc(O)c(O)cc21</smiles>

6

FIGURE 1 | Structures of coffee components investigated for aggregation inhibition activity.

DMSO (due to low solubility in water) at $25.0 \mathrm{mM}$ for in vitro screening.

\section{Chemical Synthesis of Phenylindane (6)}

Flash chromatography was performed on RediSep columns using an Isco CombiFlash system from Teledyne Isco (Lincoln, NE, United States). Thin-layer chromatography (TLC) was performed using Merck silica gel $60 \quad \mathrm{~F}_{254}$ aluminum-backed plates, and products were visualized by UV irradiation at $254 \mathrm{~nm}$. Solvents were purchased from Sigma-Aldrich (Oakville, ON, Canada) or Fisher Scientific (Markham, ON, Canada). Deionized water was acquired from an in-house supply. Proton nuclear magnetic resonance $\left({ }^{1} \mathrm{H}\right.$ NMR) spectra and carbon nuclear magnetic resonance $\left({ }^{13} \mathrm{C} \mathrm{NMR}\right)$ spectra were recorded on a $500 \mathrm{MHz}$ Agilent DD2 spectrometer (Santa Clara, CA, United States). Chemical shifts for protons are reported in parts per million ( $\mathrm{ppm}$ ) downfield from tetramethylsilane and are referenced to residual protium in the NMR solvent $\left(\mathrm{CD}_{3} \mathrm{OD}: \delta\right.$ 3.31). Chemical shifts for carbon are reported in ppm downfield from tetramethylsilane and are referenced to the carbon resonances of the solvent $\left(\mathrm{CD}_{3} \mathrm{OD}: \delta 49.0\right)$. Data are represented as follows: chemical shift $(\delta, \mathrm{ppm})$; multiplicity (s, singlet; $\mathrm{d}$, doublet; dd, doublet of doublets; ddd, doublet of doublet of doublets; q, quartet; $\mathrm{m}$, multiplet); integration; coupling constant $(J, \mathrm{~Hz})$, proton assignment. Proton resonances were assigned based on 2-D COSY, HSQC, and HMBC experiments. Mass spectra were recorded using electron spray ionization $\left(\mathrm{ESI}^{+}\right)$with a Xevo TQ-XS Tandem Triple Quadrupole Mass Spectrometer (Waters brand, Taunton, MA, United States). High-performance liquid chromatography (HPLC) was performed using a Waters Acquity UPLC $(2.1 \times 50 \mathrm{~mm}, 1.7 \mu \mathrm{m}$ particle size $)$ using gradient elution [acetonitrile/0.100\% $(v / v)$ formic acid in water $/ 0.100 \%$ $(v / v)$ formic acid] at a flow rate of $0.600 \mathrm{~mL} / \mathrm{min}$. UV detection was carried out at a wavelength of $254 \mathrm{~nm}$.

Phenylindane (6) was prepared according to modified literature procedure (Stadler et al., 1996): caffeic acid (4) (5.00 g, $27.8 \mathrm{mmol}$ ) was suspended in a solution of $2.00 \mathrm{~N}$ sulfuric acid $(100 \mathrm{~mL})$ and heated to reflux. The solution was stirred at reflux for $4 \mathrm{~h}$ and then allowed to cool to room temperature. The organic compounds were extracted by washing of the aqueous phase three times with diethyl ether. The organic extracts were combined and dried over anhydrous magnesium sulfate, filtered and concentrated under reduced pressure to give a purple solid. The crude material was purified by flash column chromatography on silica gel (gradient elution, 10-50\% diethyl ether in hexanes). Product fractions were identified by treating aliquots of the collected fractions with a small amount of $1.00 \mathrm{M}$ sodium hydroxide aqueous solution; a deep purple color is observed for phenylindane-rich fractions. Product fractions were collected and the solvent was removed under reduced pressure to yield $665 \mathrm{mg}$ of a brown/orange amorphous solid which contained ca. 25\% of an unidentified byproduct. This material was further purified using reverse-phase flash column chromatography on C18 silica gel (1:9 acetonitrile:water). Product fractions were combined 
and washed three times with methyl tert-butyl ether (MTBE). The organic extracts were combined and dried over anhydrous magnesium sulfate, filtered and concentrated under reduced pressure to give an orange amorphous solid. This material was once again purified by flash column chromatography on silica gel (6:4 MTBE:hexanes) to yield pure $\mathbf{6}$ as an orange amorphous solid (204 mg, 2.69\%), isolated as a mixture of stereoisomers (1.00:1.87 cis:trans). NMR data are consistent with previous literature reports (Stadler et al., 1996). TLC $R_{\mathrm{F}}=0.65$ (diethyl ether). cis-Isomer: ${ }^{1} \mathrm{H}$ NMR $\left(500 \mathrm{MHz}, \mathrm{CD}_{3} \mathrm{OD}\right): \delta$ (ppm) 6.69 $\left(\mathrm{d}, 1 \mathrm{H}, J=8.0 \mathrm{~Hz}, \mathrm{H}-5^{\prime}\right), 6.63(\mathrm{~d}, 1 \mathrm{H}, J=0.9 \mathrm{~Hz}, \mathrm{H}-7), 6.60(\mathrm{~d}, 1 \mathrm{H}$, $J=2.1 \mathrm{~Hz}, \mathrm{H}-2^{\prime}$ ), 6.53 (ddd, $\left.1 \mathrm{H}, J=8.1,2.1,0.4 \mathrm{~Hz}, \mathrm{H}-6^{\prime}\right), 6.27$ (d, $1 \mathrm{H}, J=1.0 \mathrm{~Hz}, \mathrm{H}-4), 3.94$ (dd, $1 \mathrm{H}, J=10.6,7.1 \mathrm{~Hz}, \mathrm{H}-1), 3.01$ (m, $1 \mathrm{H}, \mathrm{H}-3), 2.58(\mathrm{dd}, 1 \mathrm{H}, J=12.0,6.9 \mathrm{~Hz}, \mathrm{H}-2), 1.43(\mathrm{dd}, 1 \mathrm{H}$, $J=12.0,10.4 \mathrm{~Hz}, \mathrm{H}-2), 1.28\left(\mathrm{~d}, 1 \mathrm{H}, J=6.7 \mathrm{~Hz}, \mathrm{CH}_{3}\right) .{ }^{13} \mathrm{C} \mathrm{NMR}$ (125 MHz, $\left.\mathrm{CD}_{3} \mathrm{OD}\right): \delta$ (ppm) 146.2, 145.2, 144.9, 144.6, 141.1, 139.7, 138.7, 120.7, 116.1, 116.1, 112.4, 110.5, 51.0, 48.4, 39.0, 20.1. trans-Isomer: ${ }^{1} \mathrm{H}$ NMR $\left(500 \mathrm{MHz}, \mathrm{CD}_{3} \mathrm{OD}\right): \delta(\mathrm{ppm}) 6.65(\mathrm{~d}, 1 \mathrm{H}$, $\left.J=8.0 \mathrm{~Hz}, \mathrm{H}-5^{\prime}\right), 6.64(\mathrm{~s}, 1 \mathrm{H}, \mathrm{H}-7), 6.49\left(\mathrm{~d}, 1 \mathrm{H}, J=2.1 \mathrm{~Hz}, \mathrm{H}-2^{\prime}\right)$, $6.44\left(\mathrm{dd}, 1 \mathrm{H}, J=8.1,2.2 \mathrm{~Hz}, \mathrm{H}-6^{\prime}\right), 6.38(\mathrm{~d}, 1 \mathrm{H}, J=0.8 \mathrm{~Hz}, \mathrm{H}-$ 4), $4.13(\mathrm{dd}, 1 \mathrm{H}, J=8.0,5.7 \mathrm{~Hz}, \mathrm{H}-1), 3.19(\mathrm{~m}, 1 \mathrm{H}, \mathrm{H}-3), 2.14$ (ddd, $1 \mathrm{H}, J=12.5,7.6,5.9 \mathrm{~Hz}, \mathrm{H}-2), 2.05$ (ddd, $1 \mathrm{H}, J=12.5,8.1$, $5.5 \mathrm{~Hz}, \mathrm{H}-2), 1.17\left(\mathrm{~d}, 1 \mathrm{H}, J=6.7 \mathrm{~Hz}, \mathrm{CH}_{3}\right) .{ }^{13} \mathrm{C} \mathrm{NMR}(125 \mathrm{MHz}$, $\left.\mathrm{CD}_{3} \mathrm{OD}\right): \delta$ (ppm) 146.1, 145.4, 145.1, 144.3, 141.5, 139.6, 138.7, $120.1,116.1,115.7,112.7,111.0,50.0,46.7,38.9,21.3$. HRMS (ESI, $\mathrm{m} / z$ ) Calculated for $\left[\mathrm{C}_{16} \mathrm{H}_{16} \mathrm{O}_{4}\right](\mathrm{M})^{+} 272.1043$; Found 272.1047 . Calculated for $\left[\mathrm{C}_{16} \mathrm{H}_{15} \mathrm{O}_{4}\right](\mathrm{M}-\mathrm{H})^{+}$271.0965; Found: 271. 0970.

\section{$\beta$-Amyloid ThT Aggregation Assay}

This assay was adapted from LeVine (1993). A $\beta_{1-40}(>95 \%)$ was purchased from AnaSpec (Freemont, CA, United States) and stored at $-80^{\circ} \mathrm{C}$. All other reagents were of the highest available purity, purchased from Sigma-Aldrich (Oakville, ON, Canada), and used without further purification. All water used in the assays was micropore filtered and deionized (MilliQ $\left.{ }^{\circledR}\right) . A \beta_{1-40}$ $(1.00 \mathrm{mg})$ was dissolved in hexafluoro-2-propanol (HFIP) and sonicated for $30 \mathrm{~min}$ to disassemble any pre-formed aggregates. HFIP was removed using a stream of argon gas prior to dissolution of $\mathrm{A} \beta_{1-40}$ in $1.00 \mathrm{~mL}$ Tris base $(20.0 \mathrm{mM}, \mathrm{pH}$ 10.0) using vortex and $10 \mathrm{~min}$ sonication. The solution was then further diluted with $4.70 \mathrm{~mL}$ of Tris base followed by adjusting to $\mathrm{pH} 7.40$ using concentrated hydrochloric acid and then filtered using a $0.200 \mu \mathrm{m}$ syringe filter. The pretreated $\mathrm{A} \beta_{1-40}$ was diluted with an equal volume $(5.70 \mathrm{~mL})$ of $8.00 \mu \mathrm{M}$ ThT in Tris $(20.0 \mathrm{mM}, \mathrm{pH} 7.40,300 \mathrm{mM} \mathrm{NaCl})$ and $200 \mu \mathrm{L}$ aliquots of this solution $\left[20.0 \mu \mathrm{M} \mathrm{A} \beta_{1-40}\right.$ and $4.00 \mu \mathrm{M}$ ThT in Tris $(20.0 \mathrm{mM}, \mathrm{pH} 7.40,150 \mathrm{mM} \mathrm{NaCl})]$ were added to wells of a black polystyrene 96-well plate. $4.00 \mu \mathrm{L}$ of test compound solutions at various concentrations were added to each well. Each sample was performed in triplicate and MilliQ ${ }^{\circledR}$ water alone served as a vehicle control. Plates were sealed and incubated in a microplate reader (Tecan Genios) at $37.0^{\circ} \mathrm{C}$ with fluorescence measurements recorded $\left(\lambda_{\mathrm{ex}}=450 \mathrm{~nm}\right.$, $\lambda_{\mathrm{em}}=480 \mathrm{~nm}$ ) every $15 \mathrm{~min}$ after first being shaken at high intensity for $15 \mathrm{~s}$ and then allowed to settle for $10 \mathrm{~s}$ before each reading.

\section{$\beta$-Amyloid Oligomerization Assay}

This assay was adapted from LeVine (2006). Biotinylated $A \beta_{1-42}$ was purchased from AnaSpec (Freemont, CA, United States). An ELISA plate (Costar 9018) was coated with $50.0 \mu \mathrm{L}$ of a stock solution containing $1.00 \mu \mathrm{g} / \mathrm{mL}$ NeutrAvidin in sodium phosphate buffer $(10.0 \mathrm{mM}, \mathrm{pH} 7.50)$. The plate was sealed and stored at $4^{\circ} \mathrm{C}$ overnight prior to blocking for $2 \mathrm{~h}$ at room temperature with $200 \mu \mathrm{L} /$ well of OFB-T buffer [ $20.0 \mathrm{mM}$ sodium phosphate, $150 \mathrm{mM} \mathrm{NaCl}, \mathrm{pH} 7.50,0.100 \%(v / v)$ Tween 20]. Then, $20.0 \mu \mathrm{L}$ of $\mathrm{A} \beta_{1-42}$ stock solution $(0.100 \mathrm{mg} / \mathrm{mL})$ was treated with HFIP and dried under a stream of argon. One hundred microliter of trifluoroacetic acid (TFA) was added to the tube and the sample was dissolved using a vortex mixer prior to drying under a stream of argon. HFIP was added and dried under a stream or argon to remove residual TFA. The biotinylated $\mathrm{A} \beta_{1-42}$ was then dissolved in $870 \mu \mathrm{L}$ of DMSO, and $2.00 \mu \mathrm{L}$ of the solution was added to each well of a 96-well polypropylene plate (Costar 3365) followed by $100 \mu \mathrm{L}$ of test compound diluted in OFB-T buffer (various concentrations). The plate was incubated for $1 \mathrm{~h}$ at room temperature without shaking, and then stopped by the addition of $50.0 \mu \mathrm{L}$ of $0.300 \%(v / v)$ Tween 20 in MilliQ ${ }^{\circledR}$ water. $50.0 \mu \mathrm{L}$ of the biotinylated $\mathrm{A} \beta_{1-42} /$ compound solutions was added to each well of the NeutrAvidin ${ }^{\mathrm{TM}}$-coated plate (after removing blocking solution) and the plate was sealed and incubated for $2 \mathrm{~h}$ with shaking at $150 \mathrm{rpm}$. The plate was washed three times with TBST solution $[20.0 \mathrm{mM}$ Tris- $\mathrm{HCl}$, $34.0 \mathrm{mM}$ sodium chloride, $\mathrm{pH} 7.50,0.100 \%(v / v)$ Tween 20], then $50.0 \mu \mathrm{L}$ of Streptavidin-HRP $(1: 20,000)$ in OFB-T buffer was added and the plate was sealed and incubated for $1 \mathrm{~h}$ with shaking at $150 \mathrm{rpm}$. The plate was again washed three times with TBST, followed by addition of $100 \mu \mathrm{L}$ of tetramethylbenzidine $/ \mathrm{H}_{2} \mathrm{O}_{2}$ substrate solution to each well. The reaction was stopped after $10-30 \mathrm{~min}$ by the addition of $100 \mu \mathrm{L}$ of $2.00 \%(v / v)$ aqueous sulfuric acid prior to reading absorbance at $450 \mathrm{~nm}$ in a plate reader.

\section{Preparation of Tau Protein}

Human tau 40 (tau) cDNA was amplified by polymerase chain reaction (PCR) with tau forward primer (5'GCTGAGCCCCGCCAGGAGTTCG-3') and tau reverse primer (5'-TCACAAACCCTGCTTGGCCAGG-3') using Taq DNA polymerase (ThermoFisher Scientific, Waltham, MA, United States) and was cloned into Champion pET SUMO vector (ThermoFisher Scientific, Waltham, MA, United States) by using TA cloning. After transforming into TOP10 E. coli strain, colonies with correct orientation were selected by colony PCR with T7 reverse primer (5'-TAGTTATTGCTCAGCGGTGG- $\left.3^{\prime}\right)$ and tau internal forward primer (5'-CGCATGGTCAGTAAAAGCAAA$\left.3^{\prime}\right)$. Plasmid DNAs were prepared, sequenced and the one with correct sequence was selected. pET SUMO tau vector was then transformed into BL21(DE3) E. coli strain for the expression of the gene. BL21(DE3) E. coli with pET SUMO tau vector were grown in media71757 (Overnight Express ${ }^{\mathrm{TM}}$ Instant LB Medium - Novagen with kanamycin). Expression was maintained for $7 \mathrm{~h}$ before harvesting the cells by centrifugation. Harvested E. coli were lysed by sonication in the presence of 
$1.00 \%(v / v)$ Triton $\mathrm{X}-100 / 50.0 \mathrm{mM}$ Tris- $\mathrm{HCl} / \mathrm{pH} 7.40 / 500 \mathrm{mM}$ $\mathrm{NaCl} / \mathrm{EDTA}$-free protease inhibitors cocktail (Roche, Germany) in ice. Soluble lysate was recovered after removing insoluble debris by centrifugation at $20,000 \times g$. SUMO-tau with $6 \times$ His tag was purified by elution through Talon IMAC resin (Clonetech, Mountain View, CA, United States) and the eluent was dialyzed against $50.0 \mathrm{mM}$ Tris- $\mathrm{HCl} / \mathrm{pH} 7.40 / 150 \mathrm{mM}$ $\mathrm{NaCl} / 1.00 \mathrm{mM}$ dithiothreitol/0.200\% $(v / v) \mathrm{NP} 40.6 \times$ His-SUMO tag was cleaved using SUMO protease and tag-free tau protein was recovered by elution through Talon IMAC column. The tag-free tau protein was further purified by preparative reversedphase HPLC using a C18 column $(150 \times 21.2 \mathrm{~mm}, 5.00 \mu \mathrm{m}$ particle size) using gradient elution [1-30\% acetonitrile/ $0.100 \%$ $(v / v)$ formic acid in MilliQ ${ }^{\circledR}$ water/0.100\% $(v / v)$ formic acid] at a flow rate of $4.00 \mathrm{~mL} / \mathrm{min}$. UV detection was carried out at a wavelength of $220 \mathrm{nM}$.

\section{Tau ThS Aggregation Assay}

This assay was adapted from Friedhoff et al. (1998). A $4.00 \mu \mathrm{M}$ solution of tau in $5.00 \mu \mathrm{M}$ ThS in Tris $(50.0 \mathrm{mM}, \mathrm{pH} 7.40$, $10.0 \mu \mathrm{g} / \mathrm{mL}$ heparin, $1.00 \mathrm{mM}$ dithiothreitol, $50.0 \mu \mathrm{M}$ sodium azide) was prepared fresh for each experiment and $200 \mu \mathrm{L}$ aliquots were added to wells of a black polystyrene 96-well plate. $4.00 \mu \mathrm{L}$ of compound solutions at various concentrations were added to each well. Each sample was performed in triplicate and MilliQ ${ }^{\circledR}$ water alone served as a vehicle control. Plates were sealed and incubated in a microplate reader (Tecan Genios) at $37^{\circ} \mathrm{C}$ with fluorescence measurements recorded $\left(\lambda_{\text {ex }}=450 \mathrm{~nm}\right.$, $\lambda_{\mathrm{em}}=480 \mathrm{~nm}$ ) every $15 \mathrm{~min}$.

\section{$\alpha$-Synuclein Oligomerization Assay}

This assay was adapted from El-Agnaf et al. (2004). Capture antibody ( $\alpha$-synuclein 211 ) and detection antibody ( $\alpha$-synuclein 211, HRP) were purchased from Santa Cruz (Freemont, CA, United States) and stored at $4^{\circ} \mathrm{C}$. $\alpha$-Synuclein was purchased from rPeptide (Watkinsville, GA, United States) and stored at $-80^{\circ} \mathrm{C}$. A $0.100 \mathrm{mg} / \mathrm{mL}$ stock solution of $\alpha$-synuclein in DMSO was prepared, and $1.80 \mu \mathrm{g}$ of $\alpha$-synuclein was diluted with $5.00 \mathrm{~mL}$ of phosphate buffered saline (PBS), mixed well using vortex and $50.0 \mu \mathrm{L}$ aliquots were added to each well of a low-binding plate (Costar). Compound solutions of various concentrations were prepared in PBS, and $50.0 \mu \mathrm{L}$ aliquots were added to each well of the plate containing $\alpha$-synuclein. The plate was shaken at $450 \mathrm{rpm}$ for $45 \mathrm{~s}$ at $20^{\circ} \mathrm{C}$ using Eppendorf plate shaker, and then incubated for $16 \mathrm{~h}$ at room temperature without shaking. The reaction was stopped by the addition of $50.0 \mu \mathrm{L}$ of $0.300 \%(v / v)$ Tween 20 in MilliQ ${ }^{\circledR}$ water and gently mixed. $50.0 \mu \mathrm{L}$ of the capture antibody in $10.0 \mathrm{mM}$ sodium phosphate/pH 7.50 was added to each well of a high-binding ELISA plate (Costar) and allowed to sit overnight at $4^{\circ} \mathrm{C}$. The plate was blocked by addition of $250 \mu \mathrm{L}$ of TBST with $2.00 \%$ fatty acid-free bovine serum albumin at room temperature for 1$2 \mathrm{~h}$. The plate was washed three times with TBST after blocking, then $50-100 \mu \mathrm{L}$ of the test compound/ $\alpha$-synuclein solution was added to each well and the plate was sealed and incubated at room temperature for $2 \mathrm{~h}$. The plate was then washed, and $50.0 \mu \mathrm{L}$ of the detection antibody (1:1000 in TBST) was added.
The plate was sealed and incubated at room temperature for $1 \mathrm{~h}$ followed by washing three times with TBST. $100 \mu \mathrm{L}$ of tetramethylbenzidine $/ \mathrm{H}_{2} \mathrm{O}_{2}$ substrate solution was added to each well. Reaction was stopped after 25-30 min with the addition of $100 \mu \mathrm{L}$ of $0.118 \mathrm{M}$ aqueous sulfuric acid prior to reading absorbance at $450 \mathrm{~nm}$ in a plate reader.

\section{Statistical Analysis}

Data analysis was performed using GraphPad Prism software (version 7.04; GraphPad Software, San Diego, CA, United States). Differences were considered statistically significant at $P<0.05$. Fibrillization data were expressed as mean \pm standard deviation; $\%$ inhibition was calculated relative to vehicle control sample containing no analyte (taken as $0 \%$ inhibition). Group differences in \% inhibition were assessed using two-way ANOVAs to explore factors of roasting level (light roast versus dark roast) and caffeine content (caffeinated dark versus decaffeinated dark) across each concentration level; post-hoc pairwise comparisons were performed using Sidak's tests. Inhibitory effects of coffee components 2-6 were analyzed using one-way ANOVA with post-hoc Dunnett's test.

Oligomerization data were expressed as mean $\mathrm{IC}_{50} \pm$ standard deviation; $\mathrm{IC}_{50}$ values were extrapolated by fitting to a dose response curve using least squares regression $\left(R^{2}>0.9\right)$. Group differences in $\mathrm{IC}_{50}$ values were analyzed using unpaired two-tailed $t$-tests for each factor (roasting level or caffeine content). Bonferroni correction was applied for running multiple comparisons ( $P=0.05 / 2$ tests).

\section{RESULTS}

\section{Coffee Extracts and Caffeine}

We began by assessing the aggregation inhibition activity of instant coffee extracts. We chose to investigate three different types of coffee - light roast, dark roast, and decaffeinated dark roast. The effect of caffeine content would be assessed by comparing the activity of caffeinated and decaffeinated dark roast coffee extracts. Further, since it is known that different levels of roasting affect the composition of the coffee brew (Farah et al., 2005; Jaiswal et al., 2012), comparison of light versus dark roast coffee extracts was also performed. The ability of the coffee extracts to inhibit the formation of fibrillar aggregates was investigated using a ThT fluorescence assay for $A \beta$ (Figure 2) and ThS fluorescence assay for tau (Figure 3).

All three coffee extracts inhibited the fibrillization of both $\mathrm{A} \beta$ and tau proteins at $200 \mu \mathrm{g} / \mathrm{mL}$ concentration, with moderate levels of inhibition maintained for $\mathrm{A} \beta$ fibrils at $5 \mu \mathrm{g} / \mathrm{mL}$ (Table 1). A small but measurable level of inhibition was observed for tau fibrillization at $40 \mu \mathrm{g} / \mathrm{mL}$ coffee extract (Table 2). For $\mathrm{A} \beta$ fibrillization, no main effects of roast level (light versus dark) or caffeine content (dark roast versus decaffeinated dark roast) were observed. For tau fibrillization, an effect of roast level was observed $(P=0.0059)$, but only at concentrations of $200 \mu \mathrm{g} / \mathrm{mL}(P<0.0001)$; caffeine content had no effect. We were surprised to find that caffeine content did not influence aggregation inhibition, and thus performed a post-hoc analysis of 

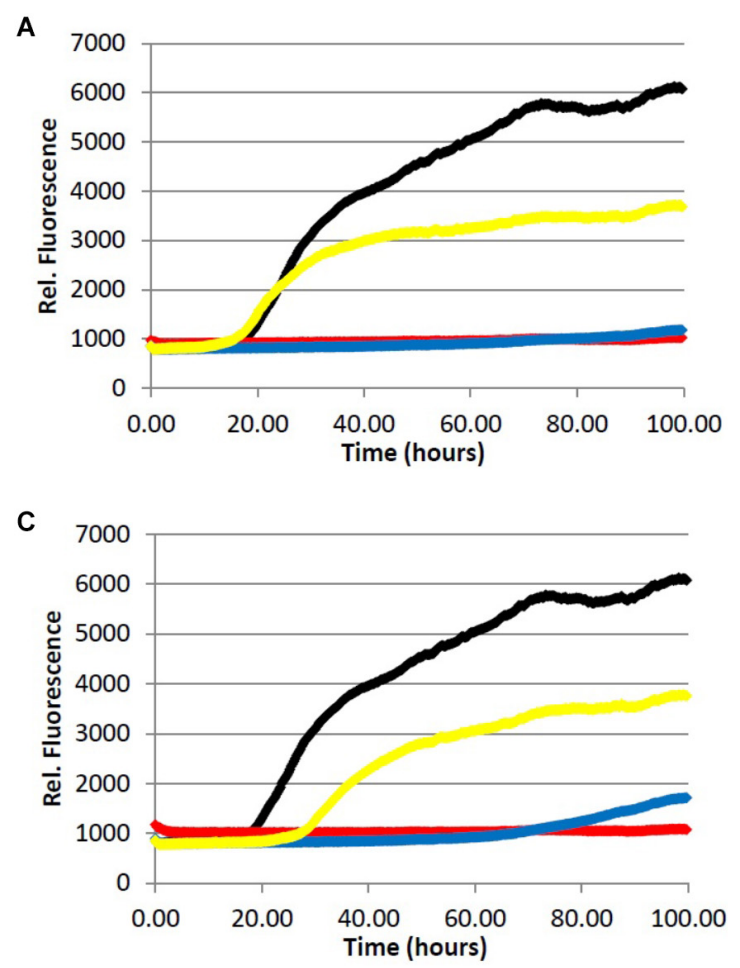
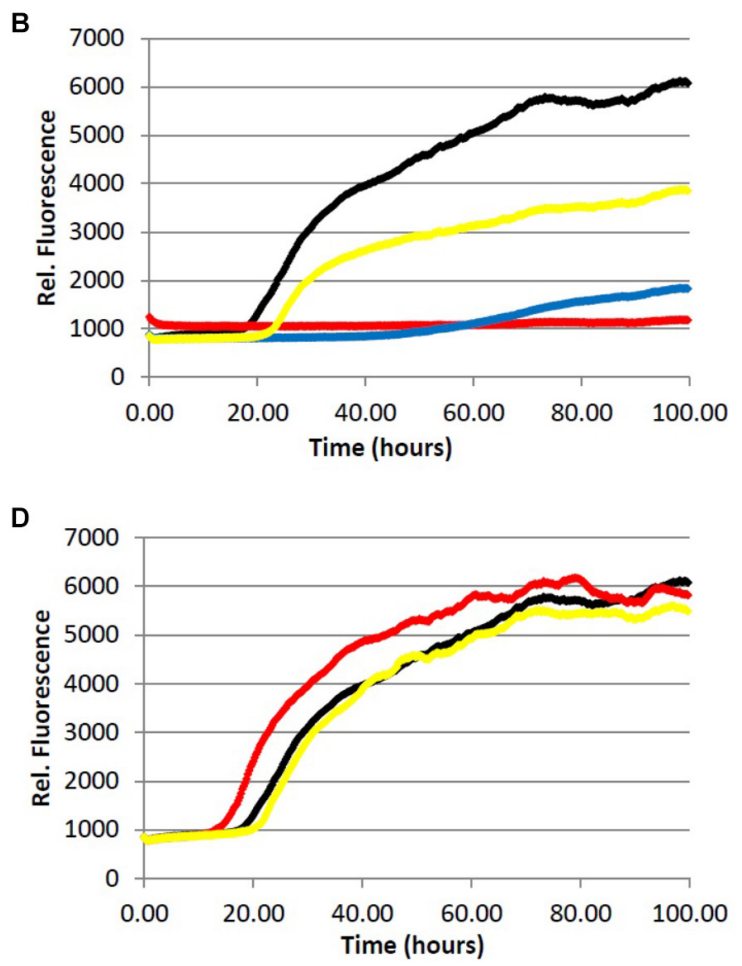

FIGURE 2 | Fibrillization of $\mathrm{A} \beta$ peptide. $20.0 \mu \mathrm{M} \mathrm{A} \beta_{1-40}$ in Tris buffer $(20.0 \mathrm{mM}, \mathrm{pH} 7.4,150 \mathrm{mM} \mathrm{NaCl})$ was incubated at $37.0^{\circ} \mathrm{C}$ in the presence of $4.0 \mu \mathrm{M}$ ThT and variable concentration of analyte. (red) $=200 \mu \mathrm{g} / \mathrm{mL}$, (blue) $=40.0 \mu \mathrm{g} / \mathrm{mL}$, (yellow) $=5.0 \mu \mathrm{g} / \mathrm{mL}$, (black) $=0.0 \mu \mathrm{g} / \mathrm{mL}$ (vehicle control). (A) Light roast instant coffee extract. (B) Dark roast instant coffee extract. (C) Decaffeinated dark roast coffee extract. (D) Caffeine $\mathbf{1 .}$

pure caffeine (1) (one-way ANOVA). No effect on fibril growth was observed relative to the vehicle control, consistent with the results for caffeinated versus decaffeinated coffee extracts.

The coffee extracts were also investigated for their ability to inhibit oligomerization of $\mathrm{A} \beta$ and $\alpha$-synuclein: $\mathrm{IC}_{50}$ values for coffee extracts and caffeine are shown in Table 3. All coffee extracts showed potent aggregation inhibition activity for $\mathrm{A} \beta$ and displayed pro-aggregation effects for $\alpha$-synuclein at concentrations above $100 \mu \mathrm{g} / \mathrm{mL}$. Furthermore, the dark roast coffee extract showed more potent aggregation inhibition activity for $A \beta$ oligomerization than the light roast coffee extract $(P<0.001)$, and decaffeinated dark roast coffee extract displayed almost identical potency to the caffeinated dark roast coffee extract $(P>0.9)$. Pure caffeine $(1)$ failed to inhibit the oligomerization of $\mathrm{A} \beta$ or $\alpha$-synuclein, and no measurable $\mathrm{IC}_{50}$ values could be obtained.

\section{Coffee Components}

In an effort to determine the active component(s) in the coffee extracts responsible for the observed aggregation inhibition activity, we assayed the compounds shown in Figure $\mathbf{1}$ as representative examples of coffee's individual components (for a rationale of how the components were chosen, see Discussion section below). All compounds were able to inhibit the formation of $\mathrm{A} \beta$ fibrils at $100 \mu \mathrm{M}$, with the exception of quinic acid (3) which was found to promote the growth of $A \beta$ fibrils relative to the control sample (Figures $\mathbf{4 A}$ and $\mathbf{5 A}$ ). Tau fibrillization (Figures $\mathbf{4 B}$ and $5 \mathrm{~B}$ ) was unaffected by compounds 2-4 at $100 \mu \mathrm{M}$, but a measurable inhibitory effect was observed for 5 and 6 (23.7 and 95.2\% inhibition, respectively). Given the potent activity of 6 toward both $A \beta$ and tau, phenylindane (6) was rescreened in the fibrillization assays at a reduced concentration of $20 \mu \mathrm{M}$; A $\beta$ fibrillization remained completely inhibited (Figure 5A), and modest levels of tau inhibition were maintained (Figure 5B). Calculated values for $\%$ inhibition of $A \beta$ and tau fibrillization by 2-6 are shown in Table 4 .

Coffee components 2-6 were also tested in the oligomerization assays, and the $\mathrm{IC}_{50}$ values for $\mathrm{A} \beta$ and $\alpha$-synuclein are shown in Table 5. While components 2, 3, and 4 were unable to inhibit the oligomerization of $\mathrm{A} \beta$ under the assay conditions, quercetin (5) and phenylindane (6) were identified as fairly potent inhibitors of $\mathrm{A} \beta$ oligomerization with $\mathrm{IC}_{50}$ values of $10.3 \mu \mathrm{M}$ and $42.1 \mu \mathrm{M}$, respectively. Oligomerization of $\alpha$-synuclein was unaffected by 2,3 , and 6, but a pro-aggregation effect for $\alpha$-synuclein was observed in the presence of caffeic acid (4) and quercetin (5) at concentrations above $100 \mu \mathrm{M}$.

\section{DISCUSSION}

\section{Caffeine}

The perceived benefits of caffeine (1) have been attributed mainly to its action as an $\mathrm{A}_{2 \mathrm{~A}}$ receptor antagonist (Svenningsson et al., 
A

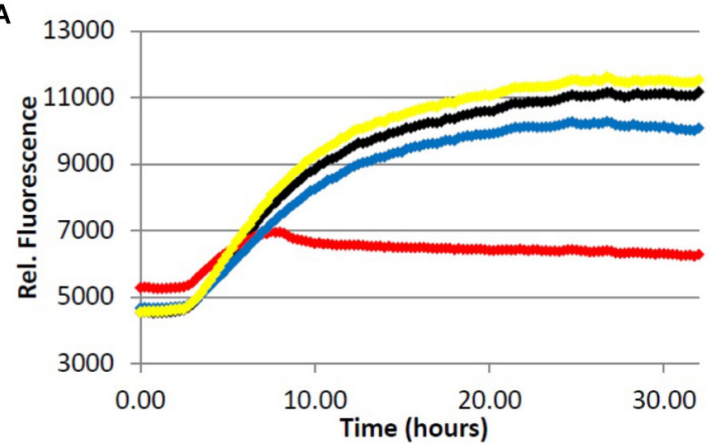

C

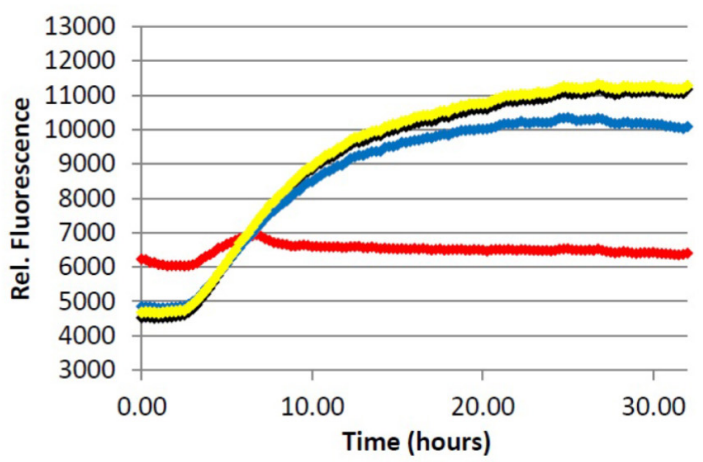

B

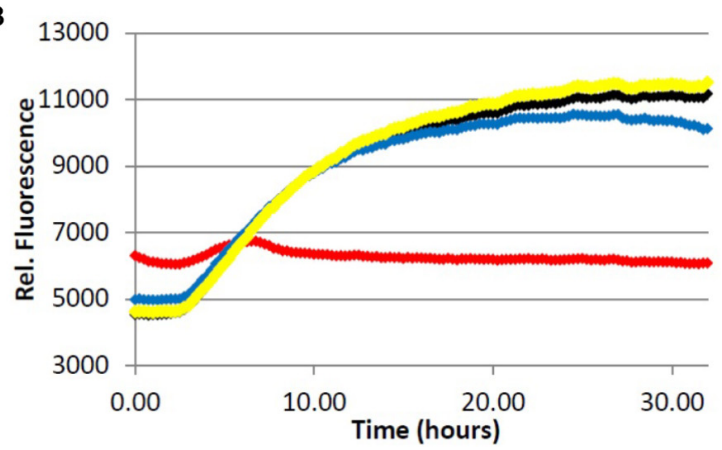

D

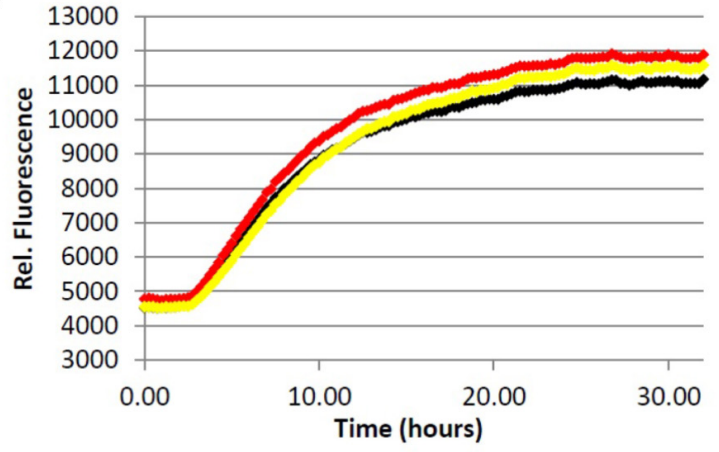

FIGURE 3 | Fibrillization of tau protein. $4.0 \mu \mathrm{M}$ tau in Tris buffer $(50.0 \mathrm{mM}, \mathrm{pH} 7.4,10.0 \mu \mathrm{g} / \mathrm{mL}$ heparin, $1.0 \mathrm{mM}$ dithiothreitol, $50.0 \mathrm{mM}$ sodium azide) was incubated at $37.0^{\circ} \mathrm{C}$ in the presence of $5.0 \mu \mathrm{M}$ ThS and variable concentration of analyte. (red) $=200 \mu \mathrm{g} / \mathrm{mL}$, (blue) $=40.0 \mu \mathrm{g} / \mathrm{mL}$, (yellow) $=5.0 \mu \mathrm{g} / \mathrm{mL}$, (black) $=0.0 \mu \mathrm{g} / \mathrm{mL}$ (vehicle control). (A) Light roast instant coffee extract. (B) Dark roast instant coffee extract. (C) Decaffeinated dark roast coffee extract. (D) Caffeine $\mathbf{1}$

TABLE 1 | Inhibition of A $\beta$ fibril formation by coffee extracts in ThT fluorescence assay. $^{\text {a }}$

\begin{tabular}{lcccc}
$\begin{array}{l}\text { Concentration Light roast } \\
(\boldsymbol{\mu g} / \mathrm{mL})\end{array}$ & $\begin{array}{c}\text { Dark roast } \\
\text { coffee extract } \\
\text { (\% inhibition) }\end{array}$ & $\begin{array}{c}\text { coffee extract } \\
\text { (\% inhibition) }\end{array}$ & $\begin{array}{c}\text { Decaffeinated } \\
\text { dark roast } \\
\text { coffee extract } \\
\text { (\% inhibition) }\end{array}$ & $\begin{array}{c}\text { Caffeine } \\
(\mathbf{1})^{\mathbf{b}}\end{array}$ \\
\hline 200 & $98.5 \pm 1.0$ & $100.1 \pm 1.8$ & $100.5 \pm 1.5$ & $-5.4 \pm 3.5$ \\
40.0 & $96.6 \pm 1.0$ & $88.4 \pm 1.6$ & $94.9 \pm 1.4$ & - \\
5.0 & $46.6 \pm 2.2$ & $46.5 \pm 2.2$ & $47.4 \pm 2.5$ & $5.7 \pm 3.0$ \\
\hline
\end{tabular}

a\% inhibition calculated relative to vehicle control sample (taken as 0\% inhibition), and is reported as the mean \pm standard deviation of three separate experiments. ${ }^{b}$ Post-hoc investigation of pure caffeine (1): no significant effect relative to vehicle control (one-way ANOVA with post-hoc Dunnett's test).

1999; Arendash et al., 2009), as the observed neuroprotective effects of caffeine have been replicated using either selective $A_{2 A}$ receptor antagonists (Canas et al., 2009) or $\mathrm{A}_{2 \mathrm{~A}}$ knockout mice (Chen et al., 2001; Canas et al., 2009). Laboratory experiments have also shown that caffeine treatment can improve working memory and decrease brain $\mathrm{A} \beta$ loads in mouse models of $\mathrm{AD}$ via suppression of both $\beta$-secretase (BACE1) and presenilin 1 (PS1) $/ \gamma$-secretase expression (Arendash et al., 2006, 2009), and improve locomotor function and attenuate dopamine depletion in the 1-methyl-4-phenyl-1,2,3,6-tetrahydropyridine (MPTP) induced toxicity model of PD in mice (Chen et al., 2001; Xu et al., 2010). However, there is still some ambiguity
TABLE 2 | Inhibition of tau fibril formation by coffee extracts in ThS fluorescence assay. ${ }^{a}$

\begin{tabular}{lcccc}
$\begin{array}{l}\text { Concentration Light roast } \\
(\mu \mathrm{g} / \mathrm{mL})\end{array}$ & $\begin{array}{c}\text { Dark roast } \\
\text { coffee extract } \\
\text { (\% inhibition) }\end{array}$ & $\begin{array}{c}\text { Decaffee extract } \\
(\% \text { inhibition) }\end{array}$ & $\begin{array}{c}\text { dark roast } \\
\text { coffee extract } \\
(\% \text { inhibition) }\end{array}$ & $\begin{array}{c}\text { Caffeine } \\
(\mathbf{1})^{\mathbf{c}}\end{array}$ \\
\hline 200 & $86.2 \pm 1.0$ & $102.6 \pm 2.4$ & $95.8 \pm 2.1$ & $-4.2 \pm 3.4$ \\
40.0 & $17.0 \pm 2.4$ & $17.7 \pm 2.4$ & $17.6 \pm 2.3$ & - \\
$5.0^{\mathrm{b}}$ & $-4.5 \pm 3.2$ & $-5.5 \pm 3.3$ & $-0.9 \pm 2.9$ & $-4.0 \pm 3.2$ \\
\hline
\end{tabular}

a\% inhibition calculated relative to vehicle control sample (taken as $0 \%$ inhibition), and is reported as the mean \pm standard deviation of three separate experiments. ${ }^{b}$ No significant effect relative to vehicle control. ${ }^{c}$ Post-hoc investigation of pure caffeine (1): no significant effect relative to vehicle control (one-way ANOVA with post-hoc Dunnett's test).

as to whether the neuroprotective effects of coffee are due to the caffeine component: in Drosophila models of $\mathrm{AD}$ and $\mathrm{PD}$, consumption of caffeinated or decaffeinated coffee led to identical neuroprotective effects whereas pure caffeine failed to provide any therapeutic outcome in this system (Trinh et al., 2010). The authors attribute the benefits of (de)caffeinated coffee to its action on the Nrf2-dependent anti-oxidative pathway, which would protect against neuroinflammation associated with the diseases. Caffeine (1) is also known to protect against degeneration of the BBB associated with AD and PD (Chen et al., 2010), and may also contribute to the neuroprotective effect of coffee. 
TABLE 3 | IC $\mathrm{IC}_{50}$ values for coffee extracts and caffeine in oligomer assays. ${ }^{a}$

\begin{tabular}{lcc}
\hline Extract & $\mathbf{A} \boldsymbol{\beta} \mathbf{I \mathbf { C } _ { 5 0 } ( \mu \mathbf { g } / \mathbf { m L } )}$ & $\begin{array}{c}\alpha \text {-synuclein } \mathbf{I C}_{\mathbf{5 0}} \\
(\mu \mathbf{g} / \mathbf{m L})\end{array}$ \\
\hline Light roast coffee extract & $40.3 \pm 4.6$ & pro-aggregate \\
Dark roast coffee extract & $9.5 \pm 1.7$ & pro-aggregate \\
Decaffeinated dark roast coffee extract & $9.4 \pm 1.5$ & pro-aggregate \\
Caffeine (1) & N.D. & N.D. \\
\hline
\end{tabular}

${ }^{a}$ Data are reported as the mean \pm standard deviation of three separate experiments. Pro-aggregate effect observed at concentrations $>100 \mu \mathrm{g} / \mathrm{mL}$. N.D. $=$ not determined $(>200 \mu \mathrm{M})$.

With respect to caffeine's ability to prevent the aggregation of amyloidogenic proteins in the brain, previous reports have suggested that caffeine (1) may inhibit the aggregation of $A \beta$ by forming hydrophobic contacts with monomers or small aggregates (Sharma and Paul, 2016; Sharma et al., 2016). In this system, a modest but observable effect of caffeine on $A \beta$ fibrillization occurs at a caffeine: $A \beta$ ratio of $3: 1$, with significant levels of inhibition achieved at or above a 10-fold molar excess of caffeine. Our results suggest that any neuroprotective properties of caffeine (1) are not due to its association with amyloidogenic proteins or protein aggregates associated with $\mathrm{AD}$, as caffeine failed to alter the aggregation profile of $\mathrm{A} \beta$ (50fold molar excess caffeine) or tau in our fibrillization assays (Figures 2D and 3D). The differences in experimental outcomes are likely due to differences in assay conditions, wherein the prior study was conducted using truncated $A \beta_{16-22}$ (rather than $\mathrm{A} \beta_{1-40}$ used in this investigation) and assays were conducted in pure water in an effort to closely replicate the computational simulations performed by the group. This surprising difference in experimental outcomes highlights the complexity of the aggregation process, and speaks to the importance of designing assay conditions which closely mimic physiological conditions to allow translation of experimental results to in vivo environments. Changes to the solution $\mathrm{pH}$, buffer composition, concentration of $\mathrm{A} \beta$ or tau etc. are known to produce variation in the experimental results (LeVine, 1993; Tiiman et al., 2015), and assay conditions which are most representative of the biological environment are more likely to be reproduced in living systems. However, there are no assurances that in vitro results will be replicated in vivo, and caution should be exercised during interpretation of in vitro data. Higher concentrations of caffeine (1) were not investigated given that the coffee extracts displayed more potent aggregation inhibition activity than caffeine at the same concentration (Figures 2 and 3, Tables 1-3).

Caffeine (1) also failed to inhibit the oligomerization of $\alpha$-synuclein, and no pro-aggregation effect was observed (Table 3). This result is consistent with a previous report on the fibrillization of $\alpha$-synuclein in the presence of caffeine (1) (Kardani and Roy, 2015): fibrils grown in the presence of caffeine (1) showed different morphology relative to fibrils grown in its absence, but the authors claim that this was not due to an interaction of caffeine (1) with the $\alpha$-synuclein protein. The lack of an observable interaction between caffeine (1) and $\mathrm{A} \beta /$ tau/ $\alpha$-synuclein would suggest that the observed activity of the coffee extracts is not due to the caffeine component. While caffeine (1) may have aggregation inhibition activity at higher concentrations, other components found in coffee are likely to be more potent inhibitors of protein aggregation. The comparable activity observed between the caffeinated and decaffeinated coffee extracts support this hypothesis.

\section{Chlorogenic Acids}

Chlorogenic acids (CGAs) are the major polyphenolic acid found in coffee beans, accounting for up to $15 \%$ dry weight of green (unroasted) coffee beans. There are nine isomers of CGAs that have been identified, with the major isomer being 5-Ocaffeoquinolinic acid (2) which accounts for approximately $60 \%$ of total CGA content (Farah and Donangelo, 2006). A typical cup of coffee contains 70-300 mg CGAs depending on the type of bean and the roasting procedure (Farah and Donangelo, 2006; Ludwig et al., 2014). CGAs are known to enter the bloodstream via intestinal absorption (Olthof et al., 2001) and have been correlated to a variety of health benefits due to their anticarcinogenic, antithrombotic, anti-inflammatory, and hypoglycemic effects (Johnston et al., 2003; Feng et al., 2005; dos Santos et al., 2006; Lee and Zhu, 2006; Park, 2009). Given the potential health benefits of CGAs, as well as its bioavailability, we felt that investigation of CGAs was warranted. Being the major CGA component, we tested 5-O-caffeoquinolinic acid (2) as a representative example of the CGAs found in coffee.

A considerable body of literature has shown that administration of CGAs to various neuronal cell lines in vitro can improve cell viability under conditions of oxidative stress or in the presence of neurotoxins (Anggreani and Lee, 2017; Nabavi et al., 2017). The neuroprotective effects were attributed to the high antioxidant capacity of CGAs, which protects cells from damage by reactive oxygen species. It has also been demonstrated that CGA treatment attenuates the pro-inflammatory response of microglia upon lipopolysaccharide (LPS) stimulation (Shen et al., 2012). Our data show that 2 is a potent inhibitor of $A \beta$ fibrillization in the ThT assay at $100 \mu \mathrm{M}$ (Figure 4A), which is in agreement with a previously reported $\mathrm{IC}_{50}$ value of ca. $40 \mu \mathrm{M}$ for inhibition of A $\beta$ fibrillization by 2 (Masuda et al., 2006). However, 2 was unable to inhibit the oligomerization of $\mathrm{A} \beta$ (Table 5), suggesting that the interaction of $\mathbf{2}$ with monomeric/oligomeric $\mathrm{A} \beta$ proteins is different than its interaction with larger $\mathrm{A} \beta$ aggregates. Such an effect has been reported previously, wherein small organic molecules inhibited the formation of larger aggregates of $\mathrm{A} \beta$ (Masuda et al., 2006), tau (Taniguchi et al., 2005), and $\alpha$-synuclein (Dedmon et al., 2005) by stabilizing the smaller oligomeric aggregates. Our data for the interaction of 2 with $\mathrm{A} \beta$ are consistent with this type of behavior.

Tau fibrillization was unaffected in the presence of 2 at 100 $\mu \mathrm{M}$ (Figure 4B), which is again consistent with literature data (Masuda et al., 2006), and no observable interaction between 2 and $\alpha$-synuclein could be detected in our oligomerization assay (Table 5). However, 2 is reported to be a reasonably potent inhibitor of $\alpha$-synuclein aggregation, with an $\mathrm{IC}_{50}$ for fibrillization inhibition of ca. $80 \mu \mathrm{M}$ (Masuda et al., 2006). The absence of an observable inhibitory effect of 2 toward $\alpha$-synuclein oligomerization would again suggest that $\mathbf{2}$ interacts differently with larger and smaller aggregates of $\alpha$-synuclein, and that $\mathbf{2}$ 

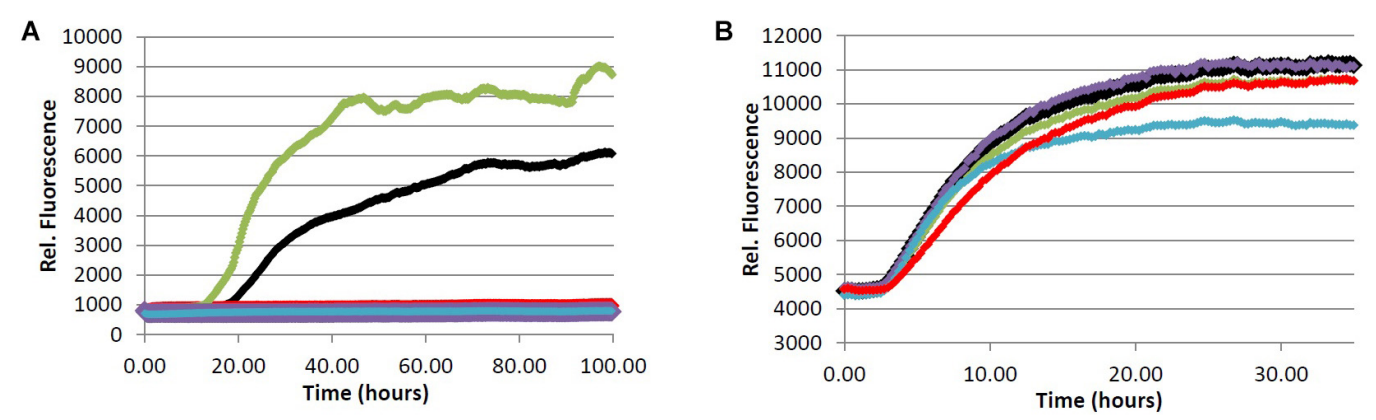

FIGURE 4 | (A) Fibrillization of A $\beta$ peptide. $20.0 \mu \mathrm{M} \mathrm{A} \beta_{1-40}$ in Tris buffer $(20.0 \mathrm{mM}, \mathrm{pH} 7.4,150 \mathrm{mM} \mathrm{NaCl})$ was incubated at $37.0^{\circ} \mathrm{C}$ in the presence of $4.0 \mu \mathrm{M}$ ThT and $100 \mu \mathrm{M}$ of analyte. (B) Fibrillization of tau protein. $4.0 \mu \mathrm{M}$ tau in Tris buffer (50.0 mM, pH 7.4, $10.0 \mu \mathrm{g} / \mathrm{mL}$ heparin, $1.0 \mathrm{mM}$ dithiothreitol, $50.0 \mathrm{mM}$ sodium azide) was incubated at $37.0^{\circ} \mathrm{C}$ in the presence of $5.0 \mu \mathrm{M}$ ThS and $100 \mu \mathrm{M}$ of analyte. (red) = chlorogenic acid (2), (green) = quinic acid (3), (purple) = caffeic acid (4), (blue) $=$ quercetin $(\mathbf{5}),($ black $)=$ no compound $($ vehicle control).
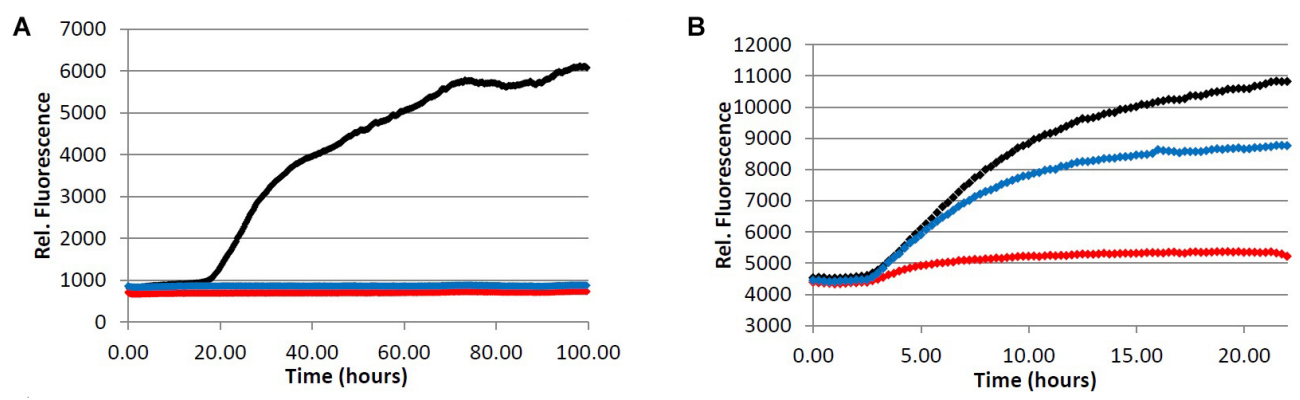

FIGURE 5 | Inhibition of fibril formation by phenylindane 6. (A) Fibrillization of $A \beta$ peptide. $20.0 \mu \mathrm{M} \mathrm{A} \beta_{1-40}$ in Tris buffer $(20.0 \mathrm{mM}, \mathrm{pH} 7.4,150 \mathrm{mM}$ NaCl) was incubated at $37.0^{\circ} \mathrm{C}$ in the presence of $4.0 \mu \mathrm{M}$ ThT and variable concentration of analyte. (B) Fibrillization of tau protein. $4.0 \mu \mathrm{M}$ tau in Tris buffer (50.0 mM, pH 7.4, $10.0 \mu \mathrm{g} / \mathrm{mL}$ heparin, $1.0 \mathrm{mM}$ dithiothreitol, $50.0 \mathrm{mM}$ sodium azide) was incubated at $37.0^{\circ} \mathrm{C}$ in the presence of $5.0 \mu \mathrm{M}$ ThS and variable concentration of analyte. $($ red $)=100 \mu \mathrm{M}$, (blue) $=20.0 \mu \mathrm{M},($ black $)=0.0 \mu \mathrm{M}$ (vehicle control)

may inhibit $\alpha$-synuclein fibrillization via stabilization of smaller oligomeric species analogous to what is observed for $\mathrm{A} \beta$ (Masuda et al., 2006). Given that soluble amyloid oligomers of $A \beta$, tau and $\alpha$-synuclein share common structural features (Kayed et al., 2003), it is reasonable to assume that 2 would exhibit similar interaction behaviors toward oligomeric $\mathrm{A} \beta$ and $\alpha$-synuclein which is consistent with our results.

Although CGAs are quite bioavailable it has been demonstrated that compounds such as $\mathbf{2}$ are unlikely to cross the BBB (Lardeau and Poquet, 2013). As such, CGAs in coffee are not likely to inhibit the aggregation of amyloidogenic proteins in the brain. Secondary mechanisms of neuroprotection cannot be ruled out; ischemic rat models that were administered CGA showed improvements in sensory-motor function and reduced levels of brain compression versus a control group (Ahn et al., 2011). Ischemic events have been correlated to AD progression (Kalaria, 2000), and it is possible that consumption of CGAs found in coffee could have neuroprotective effects in spite of the low BBB penetrance. Nonetheless, given that $\mathbf{2}$ is only able to inhibit the aggregation of $A \beta$ at relatively high concentrations, together with the lack of any observable interaction with tau or $\alpha$-synuclein, it is unlikely that $\mathbf{2}$ or other CGAs found in brewed coffee are responsible for the observed aggregation inhibition activity of the coffee extracts.
TABLE 4 | Inhibition of A $\beta$ and tau fibril formation by $2-6$ in ThT and ThS fluorescence assays. ${ }^{a}$

\begin{tabular}{lcc}
\hline Coffee component & A $\boldsymbol{\beta}$ fibril inhibition (\%) & Tau fibril inhibition (\%) \\
\hline Chlorogenic acid (2) & $97.7 \pm 0.7$ & $3.4 \pm 2.9^{\mathrm{b}}$ \\
Quinic acid (3) & $-48.8 \pm 2.8$ & $6.7 \pm 3.0^{\mathrm{b}}$ \\
Caffeic acid (4) & $99.4 \pm 0.9$ & $-2.6 \pm 3.4^{\mathrm{b}}$ \\
Quercetin (5) & $97.9 \pm 0.4$ & $23.7 \pm 2.4$ \\
Phenylindane (6) & $99.0 \pm 0.4$ & $95.2 \pm 1.7$ \\
Phenylindane (6) $^{\mathbf{c}}$ & $99.2 \pm 0.4$ & $34.4 \pm 2.4$ \\
\hline
\end{tabular}

a Samples 2-6 were screened at a concentration of $100 \mu \mathrm{M}$. Aggregation of $A \beta$ was measured using ThT fluorescence assay; data are reported as the mean \pm standard deviation of three separate experiments. Aggregation of tau was measured using ThS fluorescence assay; data are reported as the mean \pm standard deviation of three separate experiments. \% inhibition was calculated relative to vehicle control (taken as $0 \%$ inhibition). ${ }^{b}$ No significant effect relative to vehicle control. ${ }^{C}$ Experiment repeated using $20.0 \mu \mathrm{M}$ concentration; statistical significance determined using unpaired two-tailed t-test.

\section{Quinic Acid and Caffeic Acid}

During the roasting of coffee beans, CGAs are transformed via ester cleavage processes into quinic acid (3) and various phenolic cinnamates. A typical light roast coffee bean will lose approximately $25 \%$ of the initial CGA content, whereas medium and dark roast coffee beans will lose 45 and $90 \%$ of their 
TABLE 5 | IC 50 values of coffee components 2-6 in oligomer assays. ${ }^{a}$

\begin{tabular}{lcc}
\hline Coffee component & $\mathbf{A} \beta \mathbf{I C}_{\mathbf{5 0}}(\boldsymbol{\mu} \mathbf{M})$ & $\alpha$-synuclein $\mathbf{I C}_{\mathbf{5 0}}(\boldsymbol{\mu} \mathbf{M})$ \\
\hline Chlorogenic acid (2) & N.D. & N.D. \\
Quinic acid (3) & N.D. & N.D. \\
Caffeic acid (4) & N.D. & pro-aggregate \\
Quercetin (5) & $10.3 \pm 1.1$ & pro-aggregate \\
Phenylindane (6) & $42.1 \pm 1.4$ & N.D. \\
\hline
\end{tabular}

${ }^{a}$ Data are reported as the mean \pm standard deviation of three separate experiments. Pro-aggregate effect observed at concentrations $>100 \mu \mathrm{M}$. N.D. = not determined $(>200 \mu \mathrm{M})$.

CGA content, respectively (Trugo and Macrae, 1984; Ludwig et al., 2014). The majority of CGA that is "lost" during roasting is incorporated into melanoidans via the Maillard reaction. Melanoidins, though indigestible, may serve a prebiotic function by promoting the growth of beneficial types of gut bacteria and acting as dietary fiber (Reichardt et al., 2009), but were omitted from our investigation on the basis that they would not be absorbed into the bloodstream. Caffeic acid (4), which is readily bioavailable (Olthof et al., 2001), was chosen as a representative example of the phenolic cinnamates found in brewed coffee, as it is formed via ester cleavage of 5-O-caffeoquinolinic acid (2) [the major CGA component found in coffee beans (Farah and Donangelo, 2006)]. Quinic acid (3) was also tested in the protein aggregation assays, although it is worth noting that some free quinic acid (3) is converted to the 1,5-lactone during roasting (Farah and Donangelo, 2006). However, 3 displayed no observable activity as an aggregation inhibitor of $\mathrm{A} \beta$, tau or $\alpha$-synuclein.

Caffeic acid (4) is known to have antioxidant properties (Guillot et al., 1996; Gulcin, 2006), and the related ester derivative rosmarinic acid has been shown to inhibit the fibrillization of $\mathrm{A} \beta$, tau and $\alpha$-synuclen in vitro (Masuda et al., 2006). In line with these previous experiments, our assays show that $\mathbf{4}$ is an effective inhibitor of $A \beta$ fibrillization (Figure 4A), yet no inhibitory effect toward $A \beta$ oligomerization was observed (Table 5). 4 was also unable to inhibit the fibrillization of tau (Figure 4B), the other hallmark protein aggregate of AD. The similar behavior of $\mathbf{2}$ and 4 toward $A \beta$ and tau would suggest that the observed activity of $\mathbf{2}$ is due to the hydroxycinnamic acid moiety (i.e., 4) given that quinic acid (3) had no observable inhibitory effect in the aggregation assays. Of note, 4 was observed to induce aggregation of $\alpha$-synuclein at concentrations above $100 \mu \mathrm{M}$ (Table 5), which could have a neuroprotective effect by promoting Lewy body formation and thus reducing the concentration of toxic oligomer species in the brain (Pinotsi et al., 2016; Ono, 2017). However, the high concentration of $\mathbf{4}$ required to induce aggregation of $\alpha$-synuclein is not likely to accumulate in vivo.

Despite the capacity of $\mathbf{4}$ and its derivatives to enter the bloodstream, it has been demonstrated that compounds of this type are not likely to penetrate the BBB (Lardeau and Poquet, 2013). Thus it is unlikely that any neuroprotective effects of coffee are derived from these components. However, a secondary mechanism involving the action of polyphenols on the gut microbiome (Olthof et al., 2001; Johnston et al., 2003) cannot be ruled out, particularly in PD where environmental factors are suggested to contribute to the pathology of the disease (Di Monte et al., 2002; Patel et al., 2005). Changes in hormone secretion and molecular absorption could ultimately lead to less accumulation of neurotoxic compounds in the brain, although further investigation is required to identify such an effect. Nonetheless, given that $\mathbf{3}$ and $\mathbf{4}$ did not inhibit the oligomerization of $\mathrm{A} \beta$, and no aggregation inhibition activity was observed for tau, it is unlikely that these coffee components are responsible for the observed activity of the coffee extracts.

\section{Quercetin}

While caffeine and CGAs represent the main components found in coffee beans, a variety of flavonoids have also been identified, albeit in lower concentrations. Quercetin (5), a known coffee flavonoid, is reported to have antioxidant properties which help mitigate oxidative stress and inflammation (Guillot et al., 1996; Laura et al., 2011). It has also been demonstrated that 5 can increase glutathione (GSH) expression, providing additional mechanisms of antioxidant/anti-inflammatory neuroprotection (Lee et al., 2016). In fact, it has recently been suggested that quercetin (5) rather than caffeine (1) is the component which is responsible for the neuroprotective effects of coffee (Lee et al., 2016), although the authors suggest a mechanism based on antioxidant/anti-inflammatory pathways (inhibition of protein aggregation was not investigated in this report). Pharmacokinetic data has shown that $\mathbf{5}$ and its metabolites accumulate in the brains of rats (Ishisaka et al., 2011) despite the low bioavailability [approximately 20\% absorption following oral administration (Chen et al., 2005)].

Consistent with previous reports (Masuda et al., 2006; Matos et al., 2017), we observed that 5 is a potent inhibitor of $\mathrm{A} \beta$ aggregation (Figure 4A, Table 5), yet a loading of $100 \mu \mathrm{M}$ 5 showed only a modest inhibitory effect for tau fibrillization (Figure 4B), again consistent with previous data (reported $\mathrm{IC}_{50}$ for tau fibrillization by $5>200 \mu \mathrm{M}$ ) (Masuda et al., 2006). However, in contrast to literature data, we observed that $\mathbf{5}$ was able to promote the aggregation of $\alpha$-synuclein rather than inhibit its fibrillization (Table 5) (Masuda et al., 2006). This discrepancy is likely due to the differences in assay conditions (oligomer assay versus fibril assay), which suggests that $\mathbf{5}$ interacts differently with monomeric/oligomeric $\alpha$-synuclein and its mature aggregates. Indeed, such effects have been described previously (Zhu et al., 2013); 5 inhibits the formation of $\alpha$-synuclein fibrils via stabilization of smaller oligomeric species which form prior to fibrillization. Covalent modification of the $\alpha$-synuclein monomer/oligomer by 5 leads to an increase in hydrophilic surface area, stabilizing the $\alpha$-synuclein-quercetin adduct in aqueous medium and preventing further aggregation. It has also been suggested that $\mathbf{5}$ may promote the formation of small oligomeric aggregates of $\mathrm{A} \beta$ through a similar mechanism, which have the potential to be neurotoxic (Matos et al., 2017). However, no pro-aggregation effect of 5 was observed in our $A \beta$ oligomerization assay (Table 5), and in fact 5 was shown to be an effective inhibitor of $\mathrm{A} \beta$ oligomerization $\left(\mathrm{IC}_{50}=10.3 \mu \mathrm{M}\right)$.

Our data, taken together with literature reports, suggest that quercetin (5) in brewed coffee may provide neuroprotection 
in vivo through inhibiting the aggregation of pathogenic $\mathrm{A} \beta$ in the brain in addition to its known antioxidant/anti-inflammatory properties (Sabogal-Guaqueta et al., 2015; Lee et al., 2016). However, the inability of $\mathbf{5}$ to inhibit tau fibrillization limits its efficacy as a therapeutic agent to treat protein misfolding disorders associated with $\mathrm{AD}$. In addition, the propensity of $\mathbf{5}$ to promote and stabilize oligomeric aggregates of $\alpha$-synuclein through covalent modification is a potential disadvantage of using $\mathbf{5}$ to treat PD pathology. It has also been shown that $\mathbf{5}$ can form smaller oligomeric aggregates of $\alpha$-synuclein at the expense of larger fibrillar aggregates (Zhu et al., 2013). This is another drawback, as fibril formation is suspected to be neuroprotective.

\section{Phenylindanes}

Phenylindanes are formed from hydroxylated cinnamates such as caffeic acid (4) during the roasting of coffee beans (Guillot et al., 1996; Stadler et al., 1996), and mechanisms for their formation have been proposed (Stadler et al., 1996; Frank et al., 2007). Higher concentrations of phenylindanes are found in dark roast coffees (longer roasting times) such as espressos, and are largely responsible for the bitter taste of dark roast coffee blends (Frank et al., 2007). Literature reports have shown that the phenylindanes found in coffee brews display surprisingly potent antioxidant activity (Guillot et al., 1996; Stadler et al., 1996), more potent than 5-Ocaffeoquinolinic acid (2), caffeic acid (4) and quercetin (5), but their ability to interact with amyloidogenic proteins has not yet been reported. Given the observed differences in activity between the light roast and dark roast coffee extracts (Tables 2 and 3) we felt investigation of this coffee component was warranted.

We observed that the phenylindane mixture 6 (1.00:1.87 cis:trans 6) displayed potent aggregation inhibition activity in both the $A \beta$ fibrillization assay (Figure $\mathbf{5 A}$ ) and the $A \beta$ oligomerization assay (Table 5). Further, 6 displayed more potent levels of tau aggregation inhibition (Figure 5B) than any other compound investigated. Given that the dark roast coffee extracts (both caffeinated and decaffeinated) show more potent levels of aggregation inhibition in the $\mathrm{A} \beta$ oligomer assays versus light roast coffee extract (Table 3), and higher quantities of $\mathbf{6}$ are found in darker roast coffee beans, we propose that it is the phenylindane (6) component which is largely responsible for the observed aggregation inhibition activity of coffee extracts for both $A \beta$ and tau. Given that the decaffeination procedure occurs before roasting of the coffee beans, it is reasonable to assume that similar quantities of $\mathbf{6}$ are produced in both types of dark roast coffees (assuming that roasting times are also similar).

It could be argued that the increase in roasting time from light roast to dark roast coffee beans might also lead to increased quercetin (5) concentration in dark roast coffee blends via hydrolysis of quercetin glycosides (glycoside hydrolysis may increase the concentration of quercetin aglycone 5), which might correlate with increased aggregation inhibition activity of dark roast coffee extracts. However, it has been shown that while the concentration of quercetin glycosides decreases under pyrolysis (i.e., roasting) conditions, the concentration of $\mathbf{5}$ and its derivatives (oxidation products) does not change significantly (Rohn et al., 2007). A rationale is proposed wherein 5 and its derivatives, which are inherently electrophilic, react with nucleophilic components present in the food mixture to generate polymeric composites such as tannins (Rohn et al., 2007; Oracz et al., 2015). More likely, increased roasting of coffee beans would cause a decrease in the amount of 5 . We therefore propose that it is the higher concentration of phenylindane (6) in dark roast coffee extracts that is responsible for the increase in aggregation inhibition activity of dark roast coffee extract versus light roast coffee extract in the $A \beta$ oligomerization assay (Table 3).

When 6 was tested in the $\alpha$-synuclein aggregation assay, we were unable to calculate an apparent $\mathrm{IC}_{50}$ value nor did we observe any pro-aggregation behavior (Table 5). The absence of any observable interaction between $\mathbf{6}$ and $\alpha$-synuclein would suggest that $\mathbf{6}$ is not responsible for the pro-aggregation activity of the coffee extracts. More likely, this behavior is derived from caffeic acid (4) and quercetin (5). While it is unlikely that any neuroprotective effects of coffee with respect to $\mathrm{PD}$ is due to the interaction of $\mathbf{6}$ with $\alpha$-synuclein, it is plausible that $\mathbf{6}$ could elicit a neuroprotective effect in PD pathologies by other mechanisms such as neuroinflammatory/antioxidant pathways or by altering gene/protein expression to reduce the amount of pathogenic $\alpha$-synuclein in the brain. A similar mechanism could also be operative for $\mathrm{AD}$ pathologies, although such an effect has yet to be reported in either case. Further research is thus warranted to determine if phenylindanes in coffee promote additional mechanisms of neuroprotection in cell or animal models of AD and PD.

Information on the bioavailability 6 has yet to be reported. It is known that while $\mathbf{6}$ is water soluble, it can be completely extracted into ether (99.8\%) from the water phase (Guillot et al., 1996) giving promise for oral bioavailability and $\mathrm{BBB}$ penetrance. Taken together, these results suggest that the phenylindane scaffold is a promising lead for the development of drug-like molecules to treat neurodegenerative disorders, in particular those involving the aggregation of pathogenic $\mathrm{A} \beta$ and tau (AD). Further investigation into the bioavailability and pharmacokinetics of phenylindanes in coffee, as well as their BBB penetrance is warranted.

\section{CONCLUSION}

In summary, we have quantified the aggregation inhibition activity of three instant coffee extracts (light roast, dark roast, decaffeinated dark roast) and a variety of components found in coffee (1-6) toward $A \beta$, tau and $\alpha$-synuclein. We have identified phenylindane (6) as a dual-inhibitor of $A \beta$ and tau aggregation, and propose that it is the phenylindane component of coffee that is responsible for the observed aggregation inhibition activity of the coffee extracts toward $A \beta$ and tau. While our investigation did not identify any aggregation inhibition activity of coffee extracts toward $\alpha$-synuclein, we have identified caffeic acid (4) and quercetin (5) as pro-aggregates of $\alpha$-synuclein at concentrations above $100 \mu \mathrm{M}$. 
While the perceived neuroprotective effect of coffee consumption is likely due to a combination of factors related to the various biological activities of $\mathbf{1 - 6}$, the ability of $\mathbf{6}$ to interact directly with pathogenic $A \beta$ and tau to inhibit their aggregation is noteworthy. Inhibition of $A \beta$ and tau aggregation by phenylindanes (6) in coffee can be considered as a plausible mechanism of neuroprotection in $\mathrm{AD}$ pathologies for individuals who consume coffee beverages. To our knowledge this is the first report of the aggregation inhibition activity of $\mathbf{6}$, and the phenylindane (6) scaffold should be considered for future drug discovery projects which target the protein aggregation process. The ability of 6 to reduce $A \beta$, tau and $\alpha$-synuclein loads in cell and animal models of $\mathrm{AD}$ and $\mathrm{PD}$ is currently under investigation by our group, and will be reported in due course.

\section{DATA AVAILABILITY STATEMENT}

The raw data supporting the conclusions of this manuscript will be made available by the authors, without undue reservation, to any qualified researcher.

\section{REFERENCES}

Ahn, E. H., Kim, D. W., Shin, M. J., Kwon, S. W., Kim, Y. N., Kim, D. S., et al. (2011). Chlorogenic acid improves neuroprotective effect of PEP-1-Ribosomal protein S3 against ischemic insult. Exp. Neurobiol. 20, 169-175. doi: 10.5607/ en.2011.20.4.169

Anggreani, E., and Lee, C. Y. (2017). Neuroprotective effect of chlorogenic acids against Alzheimer's disease. Int. J. Food Sci. Nutr. Diet. 6, 330-337.

Arendash, G. W., Mori, T., Cao, C., Mamcarz, M., Runfeldt, M., Dickson, A., et al. (2009). Caffeine reverses cognitive impairment and decreases brain amyloidbeta levels in aged Alzheimer's disease mice. J. Alzheimers Dis. 17, 661-680. doi: 10.3233/JAD-2009-1087

Arendash, G. W., Schleif, W., Rezai-Zadeh, K., Jackson, E. K., Zacharia, L. C., Cracchiolo, J. R., et al. (2006). Caffeine protects Alzheimer's mice against cognitive impairment and reduces brain beta-amyloid production. Neuroscience 142, 941-952. doi: 10.1016/j.neuroscience.2006. 07.021

Baeta-Corral, R., Johansson, B., and Gimenez-Llort, L. (2018). Long-term treatment with low-dose caffeine worsens BPSD-like profile in 3xTg-AD mice model of Alzheimer's disease and affects mice with normal aging. Front. Pharmacol. 9:79. doi: 10.3389/fphar.2018.00079

Barone, J. J., and Roberts, H. R. (1996). Caffeine consumption. Food Chem. Toxicol. 34, 119-129. doi: 10.1016/0278-6915(95)00093-3

Blanchard, J., and Sawers, S. J. A. (1983). The absolute bioavailability of caffeine in man. Eur. J. Clin. Pharmacol. 24, 93-98. doi: 10.1007/BF00613933

Butt, M. S., and Sultan, M. T. (2011). Coffee and its consumption: benefits and risks. Crit. Rev. Food Sci. Nutr. 51, 363-373. doi: 10.1080/1040839090358 6412

Canas, P. M., Porciuncula, L. O., Cunha, G. M., Silva, C. G., Machado, N. J., Oliveira, J. M., et al. (2009). Adenosine A2A receptor blockade prevents synaptotoxicity and memory dysfunction caused by beta-amyloid peptides via p38 mitogen-activated protein kinase pathway. J. Neurosci. 29, 14741-14751. doi: 10.1523/JNEUROSCI.3728-09.2009

Cao, C., Wang, L., Lin, X., Mamcarz, M., Zhang, C., Bai, G., et al. (2011). Caffeine synergizes with another coffee component to increase plasma GCSF: linkage to cognitive benefits in Alzheimer's mice. J. Alzheimers Dis. 25:12. doi: 10.3233/ JAD-2011-110110

Caruso, G., Distefano, D. A., Parlascino, P., Fresta, C. G., Lazzarino, G., Lunte, S. M., et al. (2017). Receptor-mediated toxicity of human amylin fragment aggregated by short- and long-term incubations with copper ions. Mol. Cell. Biochem. 425, 85-93. doi: 10.1007/s11010-016-2864-1

\section{AUTHOR CONTRIBUTIONS}

RM performed chemical synthesis and structural characterization, planned biological assays, data interpretation and drafting the manuscript. YW planned biological assays, performed all biological assays and processed all raw data obtained in biological assays. DW helped edit and revise the manuscript.

\section{FUNDING}

The authors thank the Krembil Foundation for financial support. DW thanks the Canada Research Chairs program for support as a Tier I CRC in Protein Misfolding Diseases.

\section{ACKNOWLEDGMENTS}

The authors thank A. A. Waito for helpful discussion regarding statistical analysis.

Catto, M., Aliano, R., Carotti, A., Cellamare, S., Palluotto, F., Purgatorio, R., et al. (2010). Design, synthesis and biological evaluation of indane2-arylhydrazinylmethylene-1,3-diones and indol-2-aryldiazenylmethylene-3ones as $\beta$-amyloid aggregation inhibitors. Eur. J. Med. Chem. 45, 1359-1366. doi: 10.1016/j.ejmech.2009.12.029

Chen, J.-F., Xu, K., Petzer, J. P., Staal, R., Xu, Y.-H., Beilstein, M., et al. (2001). Neuroprotection by caffeine and A2A adenosine receptor inactivation in a model of Parkinson's disease. J. Neurosci. 21:RC143.

Chen, X., Ghribi, O., and Geiger, J. D. (2010). Caffeine protects against disruptions of the blood-brain barrier in animal models of Alzheimer's and Parkinson's diseases. J. Alzheimers Dis. 20(Suppl. 1), S127-S141. doi: 10.3233/JAD-20101376

Chen, X., Yin, O. Q., Zuo, Z., and Chow, M. S. (2005). Pharmacokinetics and modeling of quercetin and metabolites. Pharm. Res. 22, 892-901. doi: 10.1007/ s11095-005-4584- 1

Chu, Y. F., Chang, W. H., Black, R. M., Liu, J. R., Sompol, P., Chen, Y., et al. (2012). Crude caffeine reduces memory impairment and amyloid beta(142) levels in an Alzheimer's mouse model. Food Chem. 135, 2095-2102. doi: 10.1016/j.foodchem.2012.04.148

Costa, J., Lunet, N., Santos, C., Santos, J., and Vaz-Carneiro, A. (2010). Caffeine exposure and the risk of Parkinson's disease: a systematic review and metaanalysis of observational studies. J. Alzheimers Dis. 20(Suppl. 1), S221-S238. doi: 10.3233/JAD-2010-091525

Dedmon, M. M., Christodoulou, J., Wilson, M. R., and Dobson, C. M. (2005). Heat shock protein 70 inhibits alpha-synuclein fibril formation via preferential binding to prefibrillar species. J. Biol. Chem. 280, 14733-14740. doi: 10.1074/ jbc.M413024200

Di Monte, D. A., Lavasani, M., and Manning-Bog, A. B. (2002). Environmental factors in Parkinson's disease. Neurotoxicology 23, 487-502. doi: 10.1016/S0161813X(02)00099-2

dos Santos, M. D., Almeida, M. C., Lopes, N. P., and de Souza, G. E. (2006). Evaluation of the anti-inflammatory, analgesic and antipyretic activities of the natural polyphenol chlorogenic acid. Biol. Pharm. Bull. 29, 2236-2240. doi: $10.1248 /$ bpb. 29.2236

El-Agnaf, O. M. A., Paleologou, K. E., Greer, B., Abogrein, A. M., King, J. E., Salem, S. A., et al. (2004). A strategy for designing inhibitors of $\alpha$-synuclein aggregation and toxicity as a novel treatment for Parkinson's disease and related disorders. FASEB J. 18, 1315-1317. doi: 10.1096/fj.03-1346fje

Farah, A., de Paulis, T., Trugo, L. C., and Martin, P. R. (2005). Effect of roasting on the formation of chlorogenic acid lactones in coffee. J. Agric. Food Chem. 53, 1505-1513. doi: 10.1021/jf048701t 
Farah, A., and Donangelo, C. M. (2006). Phenolic compounds in coffee. Braz. J. Plant Physiol. 18, 23-36. doi: 10.1590/S1677-04202006000100003

Feng, R., Lu, Y., Bowman, L. L., Qian, Y., Castranova, V., and Ding, M. (2005). Inhibition of activator protein-1, NF-kappaB, and MAPKs and induction of phase 2 detoxifying enzyme activity by chlorogenic acid. J. Biol. Chem. 280, 27888-27895. doi: 10.1074/jbc.M503347200

Frank, O., Blumberg, S., Kunert, C., Zehentbauer, G., and Hofmann, T. (2007). Structure determination and sensory analysis of bitter-tasting 4-vinylcatechol oligomers and their identification in roasted coffee by means of LC-MS/MS. J. Agric. Food Chem. 55, 1945-1954. doi: 10.1021/jf0632280

Friedhoff, P., Schneider, A., Mandelkow, E.-M., and Mandelkow, E. (1998). Rapid assembly of Alzheimer-like paired helical filaments from microtubuleassociated protein tau monitored by fluorescence in Solution. Biochemistry 37, 10223-10230. doi: 10.1021/bi980537d

Guillot, F. L., Malnoë, A., and Stadler, R. H. (1996). Antioxidant properties of novel tetraoxygenated phenylindan isomers formed during thermal decomposition of caffeic acid. J. Agric. Food Chem. 44, 2503-2510. doi: 10.1021/jf950 8155

Gulcin, I. (2006). Antioxidant activity of caffeic acid (3,4-dihydroxycinnamic acid). Toxicology 217, 213-220. doi: 10.1016/j.tox.2005.09.011

Hawco, C. L., Wang, Y., Taylor, M., and Weaver, D. F. (2016). A maple syrup extract prevents beta-amyloid aggregation. Can. J. Neurol. Sci. 43, 198-201. doi: $10.1017 /$ cjn.2015.270

Ishisaka, A., Ichikawa, S., Sakakibara, H., Piskula, M. K., Nakamura, T., Kato, Y., et al. (2011). Accumulation of orally administered quercetin in brain tissue and its antioxidative effects in rats. Free Radic. Biol. Med. 51, 1329-1336. doi: 10.1016/j.freeradbiomed.2011.06.017

Jaiswal, R., Matei, M. F., Golon, A., Witt, M., and Kuhnert, N. (2012). Understanding the fate of chlorogenic acids in coffee roasting using mass spectrometry based targeted and non-targeted analytical strategies. Food Funct. 3, 976-984. doi: 10.1039/c2fo10260a

Johnston, K. L., Clifford, M. N., and Morgan, L. M. (2003). Coffee acutely modifies gastrointestinal hormone secretion and glucose tolerance in humans: glycemic effects of chlorogenic acid and caffeine. Am. J. Clin. Nutr. 78, 728-733. doi: 10.1093/ajcn/78.4.728

Kalaria, R. N. (2000). The role of cerebral ischemia in Alzheimer's disease. Neurobiol. Aging 21, 321-330. doi: 10.1016/S0197-4580(00)00125-1

Kardani, J., and Roy, I. (2015). Understanding caffeine's role in attenuating the toxicity of alpha-synuclein aggregates: implications for risk of Parkinson's disease. ACS Chem. Neurosci. 6, 1613-1625. doi: 10.1021/acschemneuro. $5 \mathrm{~b} 00158$

Kayed, R., Head, E., Thompson, J. L., McIntire, T. M., Milton, S. C., Cotman, C. W., et al. (2003). Common structure of soluble amyloid oligomers implies common mechanism of pathogenesis. Science 300, 486-489. doi: 10.1126/ science. 1079469

Lardeau, A., and Poquet, L. (2013). Phenolic acid metabolites derived from coffee consumption are unlikely to cross the blood-brain barrier. J. Pharm. Biomed. Anal. 76, 134-138. doi: 10.1016/j.jpba.2012.12.016

Laura, M., Massimo, F., Monica, B., Laura, M., Ilaria, T., Andrea, M., et al. (2011). Dietary flavonoids: molecular mechanisms of action as anti- inflammatory agents. Recent Pat. Inflamm. Allergy Drug Discov. 5, 200-220. doi: 10.2174/ 187221311797264937

Lee, M., McGeer, E. G., and McGeer, P. L. (2016). Quercetin, not caffeine, is a major neuroprotective component in coffee. Neurobiol. Aging 46, 113-123. doi: 10.1016/j.neurobiolaging.2016.06.015

Lee, W. J., and Zhu, B. T. (2006). Inhibition of DNA methylation by caffeic acid and chlorogenic acid, two common catechol-containing coffee polyphenols. Carcinogenesis 27, 269-277. doi: 10.1093/carcin/bgi206

LeVine, H. III. (1993). Thioflavine T interaction with synthetic Alzheimer's disease $\beta$-amyloid peptides: detection of amyloid aggregation in solution. Protein Sci. 2, 404-410. doi: 10.1002/pro.5560020312

LeVine, H. III. (2006). Biotin-avidin interaction-based screening assay for Alzheimer's beta-peptide oligomer inhibitors. Anal. Biochem. 356, 265-272. doi: 10.1016/j.ab.2006.04.036

Ludwig, I. A., Mena, P., Calani, L., Cid, C., Del Rio, D., Lean, M. E., et al. (2014). Variations in caffeine and chlorogenic acid contents of coffees: what are we drinking? Food Funct. 5, 1718-1726. doi: 10.1039/c4fo 00290c
Masuda, M., Suzuki, N., Taniguchi, S., Oikawa, T., Nonaka, T., Iwatsubo, T., et al. (2006). Small molecule inhibitors of $\alpha$-synuclein filament assembly. Biochemistry 45, 6085-6094. doi: 10.1021/bi0600749

Matos, A. M., Cristóvão, J. S., Yashunsky, D. V., Nifantiev, N. E., Viana, A. S., Gomes, C. M., et al. (2017). Synthesis and effects of flavonoid structure variation on amyloid- $\beta$ aggregation. Pure Appl. Chem. 89, 1305-1320. doi: 10.1016/j. ijbiomac.2015.07.052

Mirza, S. S., Tiemeier, H., de Bruijn, R. F. A. G., Hofman, A., Franco, O. H., Kieftede Jong, J., et al. (2014). Coffee consumption and incident dementia. Eur. J. Epidemiol. 29, 735-741. doi: 10.1007/s10654-014-9943-y

Nabavi, S. F., Tejada, S., Setzer, W. N., Gortzi, O., Sureda, A., Braidy, N., et al. (2017). Chlorogenic acid and mental diseases: from chemistry to medicine. Curr. Neuropharmacol. 15, 471-479. doi: 10.2174/ 1570159X14666160325120625

Olthof, M. R., Hollman, P. C. H., and Katan, M. B. (2001). Chlorogenic acid and caffeic acid are absorbed in humans. J. Nutr. 131, 66-71. doi: 10.1093/jn/ 131.1.66

Ono, K. (2017). The oligomer hypothesis in alpha-synucleinopathy. Neurochem. Res. 42, 3362-3371. doi: 10.1007/s11064-017-2382-x

Ono, K. (2018). Alzheimer's disease as oligomeropathy. Neurochem. Int. 119, 57-70. doi: 10.1016/j.neuint.2017.08.010

Oracz, J., Nebesny, E., and Żyżelewicz, D. (2015). Changes in the flavan-3-ols, anthocyanins, and flavanols composition of cocoa beans of different Theobroma cacao L. groups affected by roasting conditions. Eur. Food Res. Technol. 241, 663-681. doi: 10.1007/s00217-015-2494-y

Park, J. B. (2009). 5-Caffeoylquinic acid and caffeic acid orally administered suppress P-selectin expression on mouse platelets. J. Nutr. Biochem. 20, 800805. doi: 10.1016/j.jnutbio.2008.07.009

Patel, S., Sinha, A., Parmar, D., and Singh, M. P. (2005). An update on the role of environmental factors in Parkinson's disease. Ann. Neurosci. 12, 79-86. doi: 10.5214/ans.0972.7531.2005.120404

Pinotsi, D., Michel, C. H., Buell, A. K., Laine, R. F., Mahou, P., Dobson, C. M., et al. (2016). Nanoscopic insights into seeding mechanisms and toxicity of alphasynuclein species in neurons. Proc. Natl. Acad. Sci. U.S.A. 113, 3815-3819. doi: $10.1073 /$ pnas. 1516546113

Reichardt, N., Gniechwitz, D., Steinhart, H., Bunzel, M., and Blaut, M. (2009). Characterization of high molecular weight coffee fractions and their fermentation by human intestinal microbiota. Mol. Nutr. Food Res. 53, 287-299. doi: 10.1002/mnfr.200700509

Rohn, S., Buchner, N., Driemel, G., Rauser, M., and Kroh, L. W. (2007). Thermal degradation of onion quercetin glucosides under roasting conditions. J. Agric. Food Chem. 55, 1568-1573. doi: 10.1021/jf063221i

Sabogal-Guaqueta, A. M., Munoz-Manco, J. I., Ramirez-Pineda, J. R., LampreaRodriguez, M., Osorio, E., and Cardona-Gomez, G. P. (2015). The flavonoid quercetin ameliorates Alzheimer's disease pathology and protects cognitive and emotional function in aged triple transgenic Alzheimer's disease model mice. Neuropharmacology 93, 134-145. doi: 10.1016/j.neuropharm.2015.01.027

Santos, C., Costa, J., Santos, J., Vaz-Carneiro, A., and Lunet, N. (2010). Caffeine intake and dementia: systematic review and meta-analysis. J. Alzheimers Dis. 20(Suppl. 1), S187-S204. doi: 10.3233/JAD-2010-091387

Sharma, B., Kalita, S., Paul, A., Mandal, B., and Paul, S. (2016). The role of caffeine as an inhibitor in the aggregation of amyloid forming peptides: a unified molecular dynamics simulation and experimental study. RSC Adv. 6, 78548-78558. doi: 10.1039/C6RA17602J

Sharma, B., and Paul, S. (2016). Action of caffeine as an amyloid inhibitor in the aggregation of Abeta16-22 peptides. J. Phys. Chem. B 120, 9019-9033. doi: $10.1021 /$ acs.jpcb.6b03892

Shen, W., Qi, R., Zhang, J., Wang, Z., Wang, H., Hu, C., et al. (2012). Chlorogenic acid inhibits LPS-induced microglial activation and improves survival of dopaminergic neurons. Brain Res. Bull. 88, 487-494. doi: 10.1016/j.brainresbull. 2012.04.010

Stadler, R. H., Welti, D. H., Stämpfli, A. A., and Fay, L. B. (1996). Thermal decomposition of caffeic acid in model systems:? identification of novel tetraoxygenated phenylindan isomers and their stability in aqueous solution. J. Agric. Food Chem. 44, 898-905. doi: 10.1021/jf950411c

Svenningsson, P., Le Moine, C., Fisone, G., and Fredholm, B. B. (1999). Distribution, biochemistry and function of striatal adenosine A2A receptors. Prog. Neurobiol. 59, 355-396. doi: 10.1016/S0301-0082(99)00011-8 
Taniguchi, S., Suzuki, N., Masuda, M., Hisanaga, S., Iwatsubo, T., Goedert, M., et al. (2005). Inhibition of heparin-induced tau filament formation by phenothiazines, polyphenols, and porphyrins. J. Biol. Chem. 280, 7614-7623. doi: 10.1074/jbc.M408714200

Tiiman, A., Krishtal, J., Palumaa, P., and Tõugu, V. (2015). In vitro fibrillization of Alzheimer's amyloid- $\beta$ peptide (1-42). AIP Adv. 5:092401. doi: 10.1063/1. 4921071

Trinh, K., Andrews, L., Krause, J., Hanak, T., Lee, D., Gelb, M., et al. (2010). Decaffeinated coffee and nicotine-free tobacco provide neuroprotection in Drosophila models of Parkinson's disease through an NRF2-dependent mechanism. J. Neurosci. 30, 5525-5532. doi: 10.1523/JNEUROSCI.4777-09. 2010

Trugo, L. C., and Macrae, R. (1984). A study of the effect of roasting on the chlorogenic acid composition of coffee using HPLC. Food Chem. 15, 219-227. doi: 10.1016/j.fct.2018.02.029

Xu, K., Xu, Y. H., Chen, J. F., and Schwarzschild, M. A. (2010). Neuroprotection by caffeine: time course and role of its metabolites in the MPTP model of
Parkinson's disease. Neuroscience 167, 475-481. doi: 10.1016/j.neuroscience. 2010.02.020

Zhu, M., Han, S., and Fink, A. L. (2013). Oxidized quercetin inhibits alphasynuclein fibrillization. Biochim. Biophys. Acta 1830, 2872-2881. doi: 10.1016/j. bbagen.2012.12.027

Conflict of Interest Statement: The authors declare that the research was conducted in the absence of any commercial or financial relationships that could be construed as a potential conflict of interest.

Copyright (C) 2018 Mancini, Wang and Weaver. This is an open-access article distributed under the terms of the Creative Commons Attribution License (CC BY). The use, distribution or reproduction in other forums is permitted, provided the original author(s) and the copyright owner(s) are credited and that the original publication in this journal is cited, in accordance with accepted academic practice. No use, distribution or reproduction is permitted which does not comply with these terms. 